DIW BERLIN

Discussion

Papers

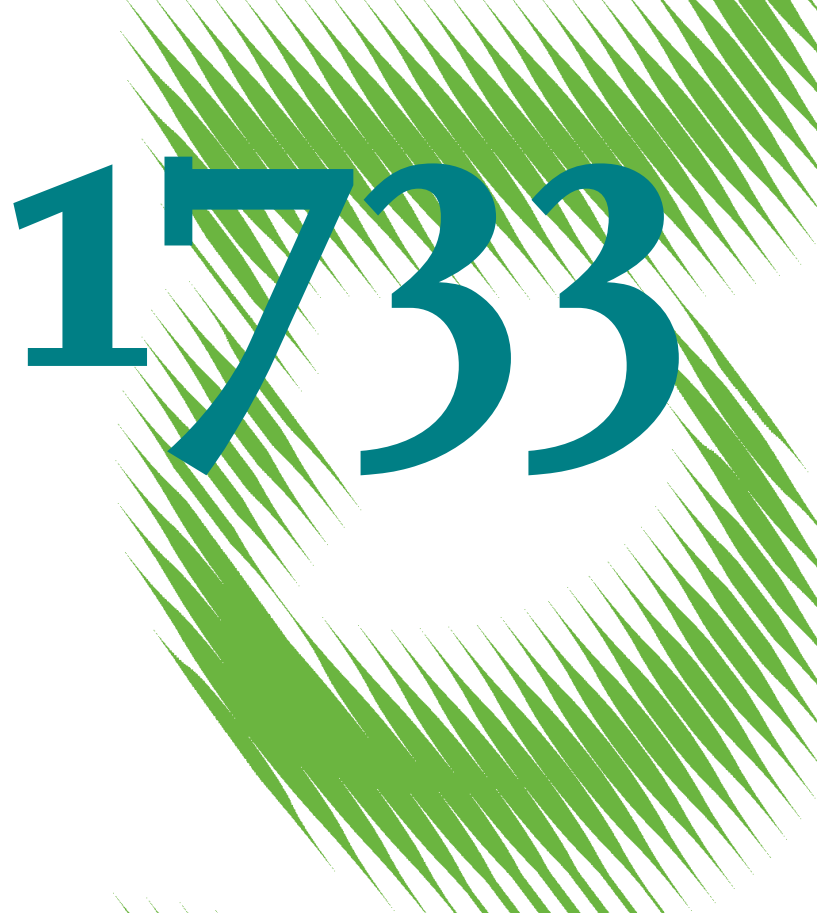

Estimating a Latent Risk Premium in Exchange Rate Futures 
Opinions expressed in this paper are those of the author(s) and do not necessarily reflect views of the institute.

IMPRESSUM

(C) DIW Berlin, 2018

DIW Berlin

German Institute for Economic Research

Mohrenstr. 58

10117 Berlin

Tel. +49 (30) $89789-0$

Fax +49 (30) $89789-200$

http://www.diw.de

ISSN electronic edition 1619-4535

Papers can be downloaded free of charge from the DIW Berlin website:

http://www.diw.de/discussionpapers

Discussion Papers of DIW Berlin are indexed in RePEc and SSRN:

http://ideas.repec.org/s/diw/diwwpp.html

http://www.ssrn.com/link/DIW-Berlin-German-Inst-Econ-Res.html 


\title{
Estimating a Latent Risk Premium in Exchange Rate Futures
}

\author{
Kerstin Bernoth, Jürgen von Hagen† Casper G. de Vries ${ }^{\ddagger}$
}

May 8, 2018

\begin{abstract}
Using exchange rates futures instead of forwards completes the maturity spectrum of the correlation between the spot return and the premium. The correlation decreases with increasing maturity, presumably due to a latent risk premium. We hypothesize that the influence of the unobserved risk factor has a contract-specific risk component. Our main contribution is to control for the omitted variable bias by using a modified version of the CCE panel estimator in combination with futures data. This renders the coefficient on the futures premium insignificantly different from one. Subsequently, the contract-specific part is related to conventional proxies of risk.
\end{abstract}

Keywords: forward premium puzzle, CCE estimation, futures rates, latent risk. JEL Classification: F31, F37, G13

${ }^{*}$ DIW Berlin and Hertie School of Governance, kbernoth@diw.de.

${ }^{\dagger}$ University of Bonn, Indiana University Kelley School of Business, and CEPR, vonhagen@uni-bonn.de.

${ }^{\ddagger}$ Erasmus University Rotterdam and Tinbergen Institute, cdevries@ese.eur.nl.

The authors like to thank Lukas Menkhoff and Andreas Pick for helpful comments. 


\section{Introduction}

According to the Expectations Hypothesis (EH), forward exchange rates should be unbiased predictors of future spot exchange rates. The hypothesis is an important building block of models of international macroeconomics and finance and manifests itself also in the form of the well-known uncovered interest parity (UIP) condition. The empirical support, however, is weak at best. Fama (1984) reported first that, in a regression of foreign exchange returns on forward premiums, the estimated slope coefficient is negative instead of being one. Since Fama (1984) a large body of empirical research has reported on what is today known as the 'forward premium puzzle' (FPP). The empirical literature falls into three categories.

The first category gives estimates for very short maturities at the intra-day or overnight horizon, see e.g. Chaboud \& Wright (2005) and Yang \& Shintani (2006). A second category looks at the other end of the spectrum, even going as far as considering multi-year horizons. Papers that fall into this category are Alexius (2003), Chinn \& Meredith (2004), and Fama \& Bliss (1987), Ding \& To (2010) and more recently Engel (2016). Most papers focus on intermediate horizons by using monthly data starting at one month up to several months. Examples in this category are Froot \& Frankel (1989), Backus et al. (2001), Baillie \& Kilic (2006), and Clarida et al. (2009).

The summary finding from these papers is that the EH may hold at the very short term and in the very long run, but significant deviations are reported at intermediate periods, mostly negative and sometimes positive. At intermediate periods, however, the evidence is rather granular as it contains relative long gaps since monthly data are used, so that only evidence at the one month, two month etc. horizons is available. A first contribution of this paper is to fill this gap. We report estimates for each day over a multi-month horizon, yielding estimates at a much finer grid than is currently available. This is possible thanks to using futures data instead of forward data. Only the early paper by Hodrick \& Srivastava (1987) uses data from three-months futures contracts to test a hypothesis related to the EH. It presents evidence rejecting this hypothesis. To the best of our knowledge no paper has exploited these data to obtain the estimates at the daily grid.

While data for forward contracts are available only for fixed maturity horizons, futures contracts have fixed delivery dates. Since futures contracts are traded in secondary markets, this makes it possible to analyze futures rates from the first to the last trading day of a given contract and to construct the full maturity spectrum of futures premiums in daily units. While the differences in trading mechanisms, default, or liquidity premiums between forward and futures contracts might cloud the comparability of the two, empirical studies suggest that this is not the case 1 Moreover, we show that for the weekly and monthly maturities,

\footnotetext{
${ }^{1}$ See e.g. Cornell \& Reinganum (1981), 1981; Hodrick \& Srivastava (1987); Chang \& Chang (1990); Polakoff and Grier, 1991.
} 
our futures data generate comparable results as forward data.

We find that the slope coefficient in the Fama regression depends significantly on the maturity horizon of the futures contract and on the observed time period. For short maturities it is generally positive, and the EH is not rejected by the data. For longer maturity horizons, however, the sign and also size of the slope coefficient depend on the time period covered. A rolling window regression reveals that when focusing on the period prior the global financial crisis, the slope coefficient tends to become negative as the maturity horizon over which expectations are formed increases. This confirms that the strength of the FPP may be a function of the maturity. However, when we focus on later periods covering the financial crisis, we observe that the FFP vanishes. The slope coefficient stays positive over the maturity spectrum and is often even much higher than the hypothesized value of one. This confirms the findings by Ding (2006), Thornton (2007) and Ding \& Ma (2011) that the coefficient estimates vary considerably across periods.

A second contribution of the current paper is that, thanks to the panel structure of the futures data, we can correct for the possible bias due to omitted variable bias. If there is an unobserved risk premium that has a (futures) contract specific component, then we may be able to correct for the bias by exploiting the large number of (cross sectional) observations from a single contract $2^{2}$ To correct for the bias we employ a modified version of Pesaran's (2006) CCE estimator. Our modified CCE estimator recovers the contract specific (part of the) risk premium by means of a constructed regressor that is the contract mean difference between the observed exchange rate returns and the futures premiums. Under the null of the $\mathrm{EH}$, the constructed regressor equals the risk premium plus an average of the contract specific error terms. Running the regression with the constructed regressor included mends for the bias. Doing this we find estimates that are insignificantly different from one at any maturity.

A third result is that thanks to the fine daily structure of the estimates across the multi-month maturity spectrum, we can fit a non-linear function that captures the shape of the bias. Due to the convexity term of this function, it follows that at some point beyond the sample maturity horizon, the bias has to decline. This is consistent with the observations from the papers that investigate the FPP at a multi-year horizon. There are numerous papers that have raised explanations for the FPP. Since this paper is empirical in nature, we do not take a stand on this, but argue that since our hypothesized specification of the risk premium is not rejected by the data, this puts restrictions on theoretical models for the risk premium.

Finally, the CCE estimator allows one to identify the latent risk premium up to an unknown scale factor. We relate the risk premium to a set of standard explanatory variables

\footnotetext{
2 According Fama (1984); Hsieh (1984); Hodrick \& Srivastava (1987); Sarno et al. (2012); Lustig et al. (2014)), the most prominent explanation of the violation of the $\mathrm{EH}$ is that the forward premium contains a timevarying risk premium that is correlated with the expected change in the exchange rate.
} 
and show that the extracted latent risk factor is closely linked to economic variables that proxy global risk, country individual economic fundamentals and currency risk. We find that it is significantly correlated with measures and determinants of currency risk that have been suggested elsewhere in the literature. These include different measures for general risk aversion of investors, measures for the cyclical stance of the US economy, US private consumption growth, and the interest differential between the two respective countries.

The remainder of this paper proceeds as follows. Section 2 investigates the relationship between the spot return and the premium over the complete maturity spectrum ranging from two days up to six months and for various time periods. Section 3 introduces the CCE estimator and gives the estimates of the premium coefficient in the presence of the common risk factor; the nature of the unobserved risk factor is analyzed in section 4 . The section 5 concludes. Some results and proofs are delegated to Appendices.

\section{Spot returns and futures premia}

Let $s_{t}$ denote the log of the spot exchange rate at time $t$ and $f_{t-m}^{t}$ the log of the futures exchange rate at time $t-m$ with delivery at time $t$ and maturity $m$. According the expectations hypothesis $(\mathrm{EH}) f_{t-m}^{t}$ should be an efficient predictor for the spot exchange rate $s_{t}$. This could be investigated empirically by regressing $s_{t}$ on $f_{t-m}^{t}$. Since exchange rates are known to be close to non-stationarity, the $\mathrm{EH}$ is usually not investigated by regressing $s_{t}$ on $f_{t-m}^{t}$, but instead the lagged spot exchange rate is subtracted from both sides to obtain stationary data:

$$
s_{t}-s_{t-m}=\alpha_{m}+\beta_{m}\left(f_{t-m}^{t}-s_{t-m}\right)+\varepsilon_{t} .
$$

Under the $\mathrm{EH}, \alpha=0$ and $\beta_{m}=1$.

Let $k$ be the index for the delivery dates of the individual futures contracts and $m$ the length of time to maturity. Each day is defined by a tuple $(m, k)$ which denotes $m$ days before the delivery date $k$. Define the log spot return $y_{n, k}=s_{0, k}-s_{m, k}$ and the futures premium $x_{m, k}=f_{m, k}^{k}-s_{m, k}$. With these definitions, we rewrite regression equation (1) as follows:

$$
y_{m, k}=\alpha_{m}+\beta_{m} x_{m, k}+\varepsilon_{m, k} .
$$

We refer to specification (2) as the Fama Regression. 


\section{$2.1 \quad$ Data}

Our empirical work uses daily closing spot exchange rates and daily closing prices for threemonths exchange rate futures contracts. Similarly as Bansal (1997), Clarida et al. (2009) and Ding \& Ma (2011) we focus on the three major currencies, the US\$/DM, US\$/GBP, and US\$/Yen. After the introduction of the Euro, we use US\$/EUR rates instead of US\$/DM rates. The delivery dates for the futures contracts are the third Wednesdays of March, June, September, and December. For each of the three currencies we focus on a total of 88 futures contracts with settlement days between June 1993 and March 2015. This starting date is chosen for two reasons. First, central banks in Europe, Japan and the US intervened heavily in the US dollar foreign exchange markets before the 1990s. $3^{3}$ The second reason is that the British Pound experienced a short period of currency crisis, when the UK was forced to leave the European Exchange Rate Mechanism (ERM) on 16 September 1992 ('Black Wednesday'). For each contract we consider the futures prices with maturities running from two days to six months or 126 business days.

\subsection{The Fama regression across the maturity spectrum}

We begin by investigating whether the relationship between the log spot return $y_{m, k}$ and the futures premium $x_{m, k}$ depends on the maturity of the futures contract, $m$. For this we estimate the Fama regression covering all 88 futures contracts but allowing for separate slope coefficients for futures prices with different maturities.

One way to estimate equation (2) is to apply an OLS estimator separately for every $m \in\{2, \ldots, 126\}\}^{4}$ In this case we would end up with 125 individual regressions each based on 88 observations. However, since futures and spot prices are correlated across maturities, these regressions would not be independent of each other and the error vectors $\varepsilon_{m, k}$ would be correlated across $m$. Taking this dependence into account leads to more efficient estimates of the standard errors. To do that, we treat equation (2) as a panel with maturity length $m$ as the cross-sectional and the maturity dates of the individual contracts as the time dimension. To estimate the panel we apply the Beck \& Kratz (1995) OLS estimator with panel-corrected standard errors. The estimator corrects for heteroskedasticity, correlation across maturities and, if necessary, serial correlation.

For all three currencies and maturity horizons, we find that the estimated intercepts $\alpha_{m}$ are small and not significantly different from zero except for US\$/Pound futures rates

\footnotetext{
${ }^{3}$ In 1985, the G-5 countries agreed with the Plaza Accord to intervene in the foreign exchange market to depreciate the US Dollar with respect to the DM and the Japanese Yen. Two years later, the G-6 countries decided with the Louvre Accord to halt the continued decline of the US Dollar caused by the Plaza Accord and to boost the exchange rate upwards.

${ }^{4}$ Dickey-Fuller tests show that the futures premium and the differenced exchange rates are stationary.
} 
with a maturity of five to seven days. Figures 1 - 3 in Appendix A plot the estimates for the slope coefficients $\beta_{m}$ together with their 95 percent confidence intervals against the maturity length, $m$. For all three currencies we find that for maturities shorter than one month (22 working days) the slope coefficient is with only a few exceptions positive. Of these, 11 are significantly different from zero for US\$/DM(Euro), seven for US\$/Yen futures contracts, and five for US\$/Pound futures contracts. The hypothesis that the Expectations Hypothesis holds $\left(\beta_{m}=1\right)$ can in most cases not be rejected. When we focus on longer maturities, we observe for the US\$/DM(Euro) and US\$/Yen futures contracts that the slope coefficients decrease with the length of the maturity $m$. For the US\$/DM(Euro) exchange rate this downward trend is more pronounced than for the US\$/Yen exchange rate. For maturities exceeding two months for the US\$/DM(Euro) futures rates and three months for the US\$/Yen futures rates the slope coefficient becomes with only a few exceptions negative but never significantly though. A different result is, however, found for US\$/Pound futures rates. Here, we do not observe this downward pattern in the estimated slope parameter. The estimated Fama coefficient varies considerably between values ranging from minus two to plus three, but without a clear trend and a stronger tendency towards positive than negative values.

Table 1: Relationship between 'Fama coefficients' and maturity length

\begin{tabular}{|c|c|c|c|}
\hline$\beta_{m}$ & $\mathrm{US} \$ / \mathrm{DM}$ & US\$/Yen & US\$/Pound \\
\hline \multirow[t]{2}{*}{ intercept } & 1.516 & 1.317 & 0.835 \\
\hline & $(0.00)$ & $(0.00)$ & $(0.00)$ \\
\hline \multirow[t]{2}{*}{ maturity } & -0.044 & -0.02 & -0.022 \\
\hline & $(0.00)$ & $(0.02)$ & $(0.01)$ \\
\hline \multirow[t]{2}{*}{ maturity $^{2}$} & 0.0002 & 0.00003 & 0.0002 \\
\hline & $(0.00)$ & $(0.58)$ & $(0.01)$ \\
\hline $\mathrm{R}^{2}$ & 0.47 & 0.33 & 0.05 \\
\hline $\mathrm{N}$ & 125 & 125 & 125 \\
\hline $\mathrm{H}_{0}$ : intercept $=1^{a)}$ & 0.01 & 0.27 & 0.40 \\
\hline
\end{tabular}

Notes: Numbers in parentheses represent $p$-values for statistical significance.

a) Test results represented in $p$-values.

To summarize the relationship between the estimated slope coefficients and the maturity length of the futures contracts, we regress the estimated $\beta_{m}$ 's on an intercept and the maturity length $m$ in levels and squared maturity values $5^{5}$ Table 11 has the results. The $R^{2}$ values suggest that maturity length explains roughly one half and one third of the variation in the

\footnotetext{
${ }^{5}$ As an alternative, we also estimated a panel of equations covering each maturity $m=2,3 \ldots$ imposing the linear quadratic relationship as a cross-equation restriction on the coefficients $\beta_{m}$. The results are similar to those reported in Table 1.
} 
estimated slope coefficients for the US\$/DM(Euro) and US\$/Yen futures, respectively. For the US\$/Pound exchange rate, however, the maturity of the futures rates explains only five percent of the variation in the estimated slope coefficients, which is in line with the graphical evidence. The estimated intercepts are positive and significant for all three currencies. The $t$-test shows that the intercept is not significantly different from one at the one percent significance level for US\$/DM(Euro) futures rates, and five percent significance level in case of the US\$/Yen and US\$/Pound future rates. The linear maturity terms have negative and significant coefficients for all three currencies. For the US\$/DM(Euro) and US\$/Pound exchange rate the squared maturity terms have significantly positive coefficients that are much smaller in absolute value.

Thus, while we estimate for the US\$/Yen futures rates a continuous decline in the Fama coefficient with increasing maturity, $m$, we estimate for the US\$/DM(Euro) and US\$/Pound futures that the slope coefficients of the 'Fama regression' first decline and become negative, but eventually increase and turn positive again, for longer maturities. For example, the results for the DM/Euro futures contracts indicate that the slope coefficient of the 'Fama regression' turns negative for maturity horizons longer than 43 days, reaches its minimum value of -0.9 at a maturity length of 110 days, and thereafter slowly increases again. Although this is not observed in our sample, the results suggest that the slope coefficient would eventually become positive again with maturities larger than 178 days. This is in line with the results of Ding \& To (2010), who focus on forward data and find that the forward premium puzzle appears to be most significant for medium maturities, while disappearing for both very short and very long maturities ${ }^{6}$

One might suggest that the result that the slope coefficients in the 'Fama regression' depend on the number of days left to maturity of a contract is an artifact due to a winding down of trading activity as the expiration day of a contract comes closer. To assure that this is not the case, we analyze the trading volume, the average daily return and the annualized volatility of the futures prices with respect to maturity. We find that the liquidity of futures markets seems to be high also for futures contracts close to expiry. For very short maturities of less than five days, the trading volume is somewhat lower, but it increases steadily in maturity and reaches its maximum seven days prior to expiry. For maturities up to 77 days the liquidity stays high. However, thereafter the trading volume decreases rapidly, which confirms the usual finding that investors tend to invest mostly in the nearest-maturity futures contract. However, the pattern of the trading volume seems to have no significant effect on the daily returns nor on the volatility of futures prices.7

\footnotetext{
${ }^{6}$ This is also consistent with recent findings in the empirical literature on the related UIP. Like the EH, UIP has been strongly rejected. However, Alexius (2003), Chinn \& Meredith (2004), and Fama \& Bliss (1987) also find evidence that UIP tends to hold for multi-year maturities.

${ }^{7}$ We have also repeated all our estimations dropping all observations for maturities longer than 77 days and
} 


\subsection{The Fama regression over time}

We investigate whether the relationship between the log spot return $y_{m, k}$ and the futures premium $x_{m, k}$ depends on the time period covered. For this, we apply a rolling window regression for a 44 quarters fixed window which results in a sequence of 45 different samples starting with futures contracts expiring between September 1993 and March 2004 and ending with futures contracts with maturity between June 2004 and March 2015. Again, we cover all futures prices with a time to maturity ranging between two days and six months ( $m=$ $2, \ldots, 126)$. The estimation results are shown in Figures 4 to 6 . For clarity reasons we only plot the magnitude of the slope coefficients without their confidence bands.

Similarly to Ding (2006), Thornton (2007) and Ding \& Ma (2011) for forward data, we observe that the magnitude of the slope coefficients $\beta_{m}$ depends significantly on the time period covered. When we focus on the earlier time periods September 1993 and March 2004, we confirm for all three currencies - including the US\$/Pound exchange rate - a negative relationship between the slope coefficient of the Fama regression and the time to maturity of the futures contract. The slope coefficients continuously decrease from positive values for short maturities to negative values fluctuating between -4 and -6 for longer maturities, which is in line with the often described FFP.

However, for all three currencies we observe a clear upward trend in the slope parameters over time. When we look at the evolution of the slope parameter for futures rates with a six month maturity, we find that the slope parameter for the US\$/DM(Euro) futures rates increases from -2.2 in the earliest subsample (September 1993 - March 2004) to 6.8 in the latest subsample (June 2004 and March 2015). For the US\$/Yen and US\$/Pound futures contracts, $\beta_{m}$ at the six months horizon increases from -3 to 1.7 and -2.4 to 4.8 , respectively. Moreover, we observe that from the moment onwards that the slope coefficients turns positive, also the negative trend between the slope coefficient and the maturity horizon of the futures contracts has vanished and the Fama coefficients becomes relatively constant. For the US\$/DM(Euro) exchange rate, this sign switch happens in the September 2000 to June 2011 window, for the US\$/Yen exchange rate in the March 2002 to December 2012 window, and for the US\$/Pound exchange rate for the June 1998 to March 2009 window. We conclude from this that it seems that when taking the period of the global financial crisis into account, the appearance of the FFP is not evident anymore.

\subsection{Robustness test with forward data}

Much of the literature has used forward instead of futures contracts to analyze the EH. To assure that our findings described above are not a special artifact of futures contracts, we also all our results were unaffected. Figures and estimation results are available on request. 
estimate the Fama regression (2) for daily observations of 1-week and 1-, 2-, 3- and 6-months forwards, covering the same currencies and time periods 8 We estimate the Fama regression with OLS and Newey-West standard errors to correct for autocorrelation in the errors due to the overlapping data structure $!^{9}$ To gauge the stability of the estimated coefficients, we split the data sample into two subperiods. The first contains the forward contracts that are sold between 1993Q2 and 2004Q4 and the second covers the contracts with selling date between 2004Q3 and 2015Q1. Figures 7 to 9 show the estimation results. Note the scarcity of observations in these figures due to the use of forwards instead of futures contracts. This drives home the advantage of using futures data which we exploit further below.

We confirm the results derived from the futures contracts. When we focus on the entire data sample running from 1993Q2 to 2015Q1, we estimate for short maturities of one week and one month a significantly positive slope coefficient that hovers at a value around one. Furthermore, we confirm for the US\$/DM(Euro) and US\$/Yen forward contracts a downward trend in the slope parameter across the maturity spectrum. The coefficients become insignificantly negative for maturities longer than one month. For US\$/Pound forward contracts we find for all maturity horizons a positive but insignificant slope coefficient.

When we look at the two subsamples, we confirm the previous findings on basis of futures data that the Fama coefficient varies considerably over time. For short maturities of one week and one month the slope coefficient is significantly positive and close to the hypothesized value of one and we confirm the EH. For longer maturities, the sign of slope coefficients depends significantly on the time period covered. For the early subsample including forward data from 1993Q2 to 2004Q4 the Fama coefficients of all three currencies show a decreasing tendency in maturity and turn negative for maturities longer than one month. For US\$/DM(Euro) forward rates, these coefficients are significant from the three month horizon onwards, for the US\$/Yen and US\$/Pound at the six months horizon, which supports the FFP. Similar to our findings based on futures data, we find that the FFP vanishes, when we focus on the later subsample running from 2004Q3 to 2015Q1.

Thus, the results found for forward contracts are very much in line with the results found for futures contracts. However, futures contracts have the advantage compared to forward contracts that they provide more detailed information on this pattern over the complete maturity spectrum measured in units of days. To summarize, we find that the slope coefficient of the Fama regression depends significantly on the maturity horizon of the futures (forward) contract and on the observed time period.

\footnotetext{
${ }^{8}$ The time periods covered with the forward rates might differ slightly from the time periods covered with futures rates. This has to do with the timing of the forwards that refers to the sell dates and the timing of the futures that refers to the settlement dates. Note that US\$/Yen forwards contracts with a maturity of three months are not available.

${ }^{9}$ For 1-week forwards, we correct for autocorrelation up to five lags, for 1-month forwards for autocorrelation of up to 21 lags, etc.
} 


\section{The Fama regression corrected for a latent risk factor}

Ever since Fama (1984), the suspicion has been that the bias in regressions of foreign exchange rate returns on the forward or futures premiums is due to an unobserved risk premium that is correlated with the explanatory variable. The full model including a risk premium $\pi_{m, k}$, thus reads:

$$
y_{m, k}=b_{m} x_{m, k}+\pi_{m, k}+e_{m, k} .
$$

Since we found no evidence for a non-zero intercept, we drop the intercept term in the subsequent analysis.

The estimates shown in Figure 4 to 6 suggest that the sign and size of correlation between the futures premium and the omitted variable varies considerably over time. This points to a contract-specific component contained in the risk premium. In addition, the size of the slope coefficient is at first a decreasing function of the maturity length and then increases again. Thus, the relevance of the risk factor also depends on the length of maturity $m$ of the futures rate. To capture these two data features, we assume that the risk premium $\pi_{m, k}$ takes the specific form $\gamma_{m} p_{k}$. Here $p_{k}$ is the common factor in the cross section of a specific contract. This allows for the observed variation over time. Depending on the maturity, the $p_{k}$ is scaled with the fixed factor $\gamma_{m}$ that is identical across contracts. The $\gamma_{m}$ captures the time to maturity specific effect as summarized by the regressions in Table 1. We introduce an estimation methodology to uncover this hypothesized structure of the risk premium. We find that the data do not reject the $\gamma_{m} p_{k}$ model. Furthermore, if the factor $\gamma_{m} p_{k}$ is included, $b_{m}=1$ is no longer rejected at any maturity $m$.

Suppose that the contract specific part of the risk premium, $p_{k}$, is random and correlated with the futures premiums from the specific contract $k$, as follows:

$$
x_{m, k}=a_{m} p_{k}+\mu_{m, k} .
$$

The factor loading $a_{m}$ is deterministic and $\mu_{m, k}$ is an additive error term.

Assumption 1. The random variables $p_{k}, \mu_{m, k}$ and $e_{m, k}$ are normally distributed with respective means and variances $p_{k} \sim N\left(p, v_{p}^{2}\right), \mu_{m, k} \sim N\left(0, \sigma_{\mu}^{2}\right)$ and $e_{m, k} \sim N\left(0, \sigma_{e}^{2}\right)$. The three random variables are all independently distributed of each other in both dimensions.

Assumption 1 is certainly not the most general assumption possible. It is for example possible to allow for the random variables to be autocorrelated. But since our futures model is a special case of the setup in Pesaran (2006), we can refer to the more general treatment there. Here we strive more for clarity and exposition in the economic dimensions than for 
generality in the econometrics dimension. We also assume that the scaling factors $\gamma_{m}$ and $a_{m}$ are deterministic, but then again one can allow for random coefficients as well as in Pesaran (2006).

We use the data to see whether we can reject this specification. If the restriction on the risk premium cannot be rejected, it implies that any theoretical model would have to fit this restriction. Which theoretical model generates such a risk premium is outside the scope of the present paper and a topic for future research. But our empirical results restrict the shape of the risk premium. Hence, our paper helps to delineate the theories that generate a risk premium which can match the data.

We first show that 3 and 4 indeed imply biased $\beta_{m}$ estimates for the Fama regression. Combining (3) and (4) we get:

$$
\begin{aligned}
y_{m, k} & =b_{m} x_{m, k}+\gamma_{m} p_{k}+e_{m, k} \\
& =\left(b_{m} a_{m}+\gamma_{m}\right) p_{k}+e_{m, k}+b_{m} \mu_{m, k} .
\end{aligned}
$$

We can then write:

$$
\begin{aligned}
\frac{1}{K} \sum_{k}^{K} x_{m, k}^{2} & =\frac{1}{K} \sum_{k}^{K}\left(a_{m} p_{k}+\mu_{m, k}\right)^{2} \\
& =a_{m}^{2} \frac{1}{K} \sum_{k}^{K} p_{k}^{2}+\frac{1}{K} \sum_{k}^{K} \mu_{m, k}^{2}+2 a_{m} \frac{1}{K} \sum_{k}^{K} p_{k} \mu_{m, k} \\
& =a_{m}^{2} v_{p}^{2}+\sigma_{\mu}^{2}+O_{p}(1 / K)+O_{p}(1 / \sqrt{K}),
\end{aligned}
$$

where order terms of the same order are only reported once..$^{10}$ The terms $O_{p}(1 / K)$ and $O_{p}(1 / \sqrt{K})$ converge to zero in probability as the number of contracts $K$ becomes large.

For the cross-product:

$$
\begin{aligned}
\frac{1}{K} \sum_{k}^{K} x_{m, k} y_{m, k}= & \frac{1}{K} \sum_{k}^{K}\left[a_{m} p_{k}+\mu_{m, k}\right]\left[\left(b_{m} a_{m}+\gamma_{m}\right) p_{k}+e_{m, k}+b_{m} \mu_{m, k}\right] \\
& =a_{m}\left(b_{m} a_{m}+\gamma_{m}\right) \frac{1}{K} \sum_{k}^{K} p_{k}^{2}+a_{m} \frac{1}{K} \sum_{k}^{K} p_{k} e_{m, k}+a_{m} b_{m} \frac{1}{K} \sum_{k}^{K} p_{k} \mu_{m, k} \\
& +\left(b_{m} a_{m}+\gamma_{m}\right) \frac{1}{K} \sum_{k}^{K} p_{k} \mu_{m, k}+\frac{1}{K} \sum_{k}^{K} e_{m, k} \mu_{m, k}+b_{m} \frac{1}{K} \sum_{k}^{K} \mu_{m, k}^{2} \\
= & a_{m}\left(b_{m} a_{m}+\gamma_{m}\right) v_{p}+b_{m} \sigma_{\mu}^{2}+O(1 / K)+O_{p}(1 / \sqrt{K}) .
\end{aligned}
$$

${ }^{10}$ Means of products like $p_{k} e_{m, k}$ are zero and their empirical counterparts $(1 / K) \Sigma p_{k} e_{m, k}$ adhere to the central limit law with rate of convergence $1 / \sqrt{K}$. Empirical second moments like $(1 / K) \Sigma p_{k}^{2}$ when multiplied by $K$ are $\chi^{2}(K)$ distributed and thus converge at rate $1 / K$. 
Consider the Fama regression from (2). Given (3), the error terms of the Fama regression are a function of the unobserved risk premium $p_{k}$ and errors $e_{m, k}$ :

$$
\varepsilon_{m, k}=\gamma_{m} p_{k}+e_{m, k}
$$

The slope coefficient of the Fama regression is then defined as:

$$
\begin{aligned}
\widehat{\beta}_{m}= & \frac{\frac{1}{K} \sum_{k}^{K} x_{m, k} y_{m, k}}{\frac{1}{K} \sum_{k}^{K} x_{m, k}^{2}} \\
= & \frac{a_{m}\left(b_{m} a_{m}+\gamma_{m}\right) v_{p}^{2}+b_{m} \sigma_{\mu}^{2}+O_{p}(1 / \sqrt{K})}{a_{m}^{2} v_{p}^{2}+\sigma_{\mu}^{2}+O_{p}(1 / \sqrt{K})} \\
& \stackrel{p}{\rightarrow} b_{m}+\frac{a_{m} \gamma_{m} v_{p}^{2}}{a_{m}^{2} v_{p}+\sigma_{\mu}^{2}}
\end{aligned}
$$

Note that this allows for the slope coefficients of the Fama regression to differ across the maturity spectrum. In particular the slope coefficient can be negative if $a_{m} \gamma_{m}$ is strongly negative. It also allows for a positive bias, or a downward bias at first and subsequently an upward bias, while eventually the bias would disappear if $a_{m} \gamma_{m} \rightarrow 0$. This would be the case, if for instance the correlation between the risk premium and the futures premium is small $\left(a_{m} \rightarrow 0\right)$ and/or when the risk premium enters the regression equation with only marginal effects $\left(\gamma_{m} \rightarrow 0\right)$. Since we have not assumed anything about the values and signs of $a_{m}$ and $\gamma_{m}$, we can capture different shapes of the bias across the maturity spectrum as recorded in the literature discussed above. We summarize this in the following result:

Proposition 1. Regardless the value of $b_{m}$ and given the assumptions regarding the error terms and $p_{k}$, the OLS estimator of the original Fama regression $\beta_{m}$ in $(2)$ is inconsistent due to the factor $\frac{a_{m} \gamma_{m} v_{p}}{a_{m}^{2} v_{p}+\sigma_{\mu}^{2}}$.

To eliminate the inconsistency, we employ a modified version of the Common Correlated Effects (CCE) estimator of Pesaran (2006). The main idea of the CCE estimator is that one can under some circumstances remedy for the bias by using cross sectional averages to construct additional regressors that capture the nature of the (unobserved) 'omitted' variable. When included, these constructed regressors may eliminate the bias. In Pesaran (2006), the cross sectional averages of the dependent and explanatory variable are both included separately as the additional regressors. In the specification above, one can show that the two 
averages are highly collinear, though. Specifically:

$$
\begin{aligned}
\frac{1}{M} \sum_{m}^{M} x_{m, k} & =\frac{1}{M} \sum_{m}^{M}\left[a_{m} p_{k}+\mu_{m, k}\right] \\
& =p_{k} \frac{1}{M} \sum_{m}^{M} a_{m}+\frac{1}{M} \sum_{m}^{M} \mu_{m, k} \\
& \sim N\left(a p, a^{2} v_{p}^{2}\right)+N\left(0, \sigma_{\mu}^{2} / M\right),
\end{aligned}
$$

where $a \equiv \frac{1}{M} \sum_{m}^{M} a_{m}$.

Similarly, for the dependent variable, using (5):

$$
\begin{aligned}
\frac{1}{M} \sum_{m}^{M} y_{m, k} & =\frac{1}{M} \sum_{m}^{M}\left[\left(b_{m} a_{m}+\gamma_{m}\right) p_{k}+e_{m, k}+b_{m} \mu_{m, k}\right] \\
& =p_{k} \frac{1}{M} \sum_{m}^{M}\left(b_{m} a_{m}+\gamma_{m}\right)+\frac{1}{M} \sum_{m}^{M}\left(e_{m, k}+b_{m} \mu_{m, k}\right) \\
& =(A+\Gamma) p_{k}+\frac{1}{M} \sum_{m}^{M}\left(e_{m, k}+b_{m} \mu_{m, k}\right),
\end{aligned}
$$

where we use shorthand notations for the sums:

$$
A=\frac{1}{M} \sum_{m}^{M} b_{m} a_{m} ; \text { and } \Gamma=\frac{1}{M} \sum_{m}^{M} \gamma_{m} .
$$

Thus, we can write:

$$
\begin{aligned}
& \frac{1}{M} \sum_{m}^{M} y_{m, k} \\
\sim & N\left((A+\Gamma) p,(A+\Gamma)^{2} v_{p}^{2}\right)+N\left(0, \sigma_{e}^{2} / M\right)+N\left(0, \frac{\sigma_{\mu}^{2}}{M} \frac{1}{M} \sum_{m}^{M} b_{m}^{2}\right) .
\end{aligned}
$$

Comparing (7) to (9), one notices that both terms are linear in the risk premium factor $p_{k}$. For large $M$ this is the dominating factor in both (7) and (9) and the cause for collinearity as the other terms vanish at speed $1 / \sqrt{M}$ (assuming that $\frac{1}{M} \sum_{m}^{M} b_{m}^{2}$ is convergent, which is definitely the case under the $\mathrm{EH}$ that $b_{m}=1$ ).

Given the collinearity of these two averages, we consider their difference and include this difference as an extra regressor to remedy for the bias. Taking the difference is also intuitive as under the EH null $\left(b_{m}=1\right)$, the constructed regressor is just equal to the cross sectional average risk premium. Denote this constructed regressor by $w_{k}$. Thus we propose 
to use:

$$
\begin{aligned}
w_{k} & \equiv \frac{1}{M} \sum_{m}^{M} y_{m, k}-\frac{1}{M} \sum_{m}^{M} x_{m, k} \\
& =(A-a+\Gamma) p_{k}+\frac{1}{M} \sum_{m}^{M}\left(e_{m, k}+\left(b_{m}-1\right) \mu_{m, k}\right) .
\end{aligned}
$$

The benefit of using futures data instead of forwards is that $M$ is large as well, so that in fact $w_{k} \simeq(A-a+\Gamma) p_{k}$. Note that $\frac{1}{M} \sum_{m}^{M} e_{m, k}=O(1 / M)$, so that 10 definitely applies under the $\mathrm{EH}$ that $b_{m}=1$; and otherwise this requires a mild condition on $b_{m}$ such as $\left|b_{m}\right|<B$ and where $B$ is some positive constant $B<\infty$. Note that under the EH null that $b_{m}=1, w_{k} \simeq \Gamma p_{k}$ if the cross sectional dimension is large. Recall that $\pi_{m, k}=\gamma_{m} p_{k}$, so that indeed in the case of the $\mathrm{EH} w_{k} \simeq(1 / M) \sum_{m}^{M} \pi_{m, k}$.

Consider the following modified CCE regression specification:

$$
y_{m, k}=b_{m} x_{m, k}+\omega_{m} w_{k}+\eta_{m, k} .
$$

We have the following result:

Proposition 2. Suppose we run the multiple regression (11), given the stated assumptions, then as $M \rightarrow \infty$ and $K \rightarrow \infty$ the coefficient estimates are:

$$
\widehat{b}_{m} \stackrel{p}{\rightarrow} b_{m}
$$

from (5), and:

$$
\widehat{\omega}_{m} \stackrel{p}{\rightarrow} \frac{\gamma_{m}}{A-a+\Gamma}
$$

Moreover, in the case that $b_{m}=1$, then:

$$
\widehat{\omega}_{m} \stackrel{p}{\rightarrow} \gamma_{m} / \Gamma
$$

Proof. See Appendix.

Inclusion of the constructed regressor $w_{k}$ in the futures regression turns $\widehat{b}_{m}$ into a consistent estimator. In particular, if $b_{m}=1$, then $\widehat{b}_{m} \rightarrow 1$ as $M \rightarrow \infty$ and $K \rightarrow \infty$. But if $b_{m} \neq 1$, the modified CCE estimator nevertheless recovers the correct value of $b_{m}$ under stated conditions in larger panels. However, in this case one would not be sure whether this is due to a failure of the stated conditions so that $\widehat{b}_{m}$ is also biased, or that the true value $b_{m} \neq 1$. The multiple regression at least enables testing for the $\mathrm{EH}$ in the presence of the 
risk premium as specified. If $\widehat{b}_{m}=1$ is not rejected, this means that the model (5) together with the results from Fama regression 2 and the modified CCE estimator offer a coherent account of the forward cum futures premium puzzle. ${ }^{11}$

Thus, we can summarize that if the futures premium is correlated with a latent risk premium $p_{k}$, the Fama regression delivers biased and inconsistent slope coefficients, while the modified CCE estimator asymptotically recovers the correct $b_{m}$ value. The latter result can also be explained more intuitively. Recall that the futures premium reads:

$$
x_{m, k}=a_{m} p_{k}+\mu_{m, k}
$$

The first part is correlated with the risk premium $\gamma_{m} p_{k}$ as both contain $p_{k}$. By including the constructed regressor $w_{k}$, which itself is correlated with the risk premium factor $p_{k}$ since $w_{k} \simeq(A-a+\Gamma) p_{k}$, the estimator $\widehat{b}_{m}$ is purged from the influence of $\gamma_{m} p_{k}$. What remains is the second part $\mu_{m, k}$. Since this term is orthogonal to the error term $e_{m, k}$ and the risk premium $\gamma_{m} p_{k}$, the estimator $\widehat{b}_{m}$ tends to yield the correct model value $b_{m}$.

With the modified CCE estimator, we can in fact recover a proxy of the contract specific risk premium $p_{k}$ and the maturity specific scalar $\gamma_{m}$. Suppose that the EH applies and $b_{m}=1$, then: $\gamma_{m}=\widehat{\omega}_{m} \Gamma$ and $p_{k} \simeq w_{k} / \Gamma$. Thus, the maturity specific scalar part of the risk premium and the contract specific risk premium are defined up to the factor $\Gamma$. In a later section we relate $p_{k}$ to economic variables that are commonly believed to shape risk premiums.

For the estimation of (11) we focus again on all futures contracts that settled between June 1993 and March $2015(k=88)$ with maturities running from two days to six months (126 days). We add again an intercept to the regression to test for its significance. We implement the modified CCE estimator in two ways. First, we allow the intercept and the coefficient $\widehat{b}_{m}$ to vary with maturities. The resulting estimates of $\widehat{b}_{m}$ are plotted in Figures 10 to 12 together with their $95 \%$ confidence interval. The figures show that the downward trend in the slope coefficient has vanished for all three currencies. The slope coefficients are now generally positive and very often significant. As shown in Table 2, a Wald-Wolfowitz runs test cannot reject at any reasonable significance level that the $\widehat{b}_{m}$ 's fluctuate are randomly around the hypothesized value of 1 , which is also an indirect evidence for the validity of Assumption 1. Regressions of the slope coefficient on the maturity and the squared maturity of the same type as in Table 1 confirm the visual impression, i.e., that neither regressor has a significant coefficient.

${ }^{11}$ There are many alternative models for which the $\widehat{b}_{m} \neq 1$. One example is the case in which there is an extra contract specific noise term $q_{k}$ included in the the errors $e_{m, k}$ such that $\varepsilon_{m, k}=\gamma_{m} p_{k}+e_{m, k}+q_{k}$. Then one shows that the modified CCE estimator $\widehat{b}_{m}$ is biased, but that the original CCE estimator, which includes the cross sectional averages of the dependent and explanatory variable separately, recovers the correct value 
Table 2: Wald-Wolfowitz Test Results

\begin{tabular}{lrrr}
\hline \hline & US $\$$ /DM & US $\$$ /Yen & US\$/Pound \\
\hline $\mathrm{N}\left(\widehat{b}_{m} \leq 1\right)$ & 73 & 77 & 63 \\
$\mathrm{~N}\left(\widehat{b}_{m}>1\right)$ & 52 & 48 & 62 \\
$\mathrm{~N}($ Runs $)$ & 68 & 65 & 63 \\
Prob $>|z|$ & 0.25 & 0.36 & 0.93 \\
\hline \hline N $($.$) stands for the number of observations; N(Runs)$ \\
gives the number of runs above and below the thresh- \\
old value of one, Prob $>|z|$ gives the p-value of the \\
hypothesis that $\widehat{b}_{m}$ fluctuates randomly around the \\
value of one.
\end{tabular}

Table 3 reports the average intercept and $\widehat{b}_{m}$ obtained from these estimates together with the standard deviations of the mean. Pesaran (2006) calls this the CCE mean group estimator. Except for the Japanese Yen, the average intercept is small in magnitude and not significantly different from zero. For all three currencies the slope coefficients are significantly positive and close to one and the Null Hypothesis that the mean group estimator equals the hypothesized value of one cannot be rejected at standard significance levels.

Next, we estimate the CCE pooled estimator, which restricts the slope coefficients $\widehat{b}_{m}$ to be the same for all maturities $m$ (see Pesaran (2006)). The lower panel of Table 3 reports these estimates. Again, we find that the slope coefficient is significantly positive. For US\$/Pound futures, we cannot reject the Null hypothesis that $\widehat{b}_{m}=1$ at all reasonable significance levels and for US\$/DM(Euro) not at the 1\%-significance level.

The relevance of adding the constructed regressor by $w_{k}$ to the standard 'Fama specification' (2) can be tested by means of the Likelihood ratio test. Table 3 reports the $p$-values of testing (11) against (2) on basis of the mean group estimator and the pooled estimator. It appears that in none of the cases one can omit the regressor $w_{k}$ on basis of its statistical significance. Moreover, the fact that $\widehat{b}_{m}$ becomes mostly significantly positive underlines that the latent factor adds new information to the estimations and that the coefficient estimates from the standard specification (2) are severely biased as claimed by Fama (1984). The CCE estimator corrects for this bias and indicates that accounting for the latent factor can be sufficient to resolve the FFP.

To gauge the robustness of the estimates, we have repeated the estimations as in section 2 and apply again a rolling window regression for a 44 quarters fixed window. The results are plotted in Figures (13) to (15). For clarity reasons we plot again only the magnitude of the slope coefficients without their confidence bands. We find that once we correct for the potential presence of a latent risk factor affecting the futures premium, the pattern of of th slope coefficient $b_{m}$. But since we lack a well defined alternative model, we only test against $b_{m}=1$. 
Table 3: Slope Coefficients from CCE Estimator

\begin{tabular}{rrrr}
\hline \hline & US\$/DM & US\$/Yen & US\$/Pound \\
\hline Mean Group Estimator & & & \\
average intercept & 0.004 & 0.073 & -0.006 \\
& $(0.86)$ & $(0.00)$ & $(0.82)$ \\
average $b$ & 0.940 & 0.979 & 0.957 \\
& $(0.05)$ & $(0.00)$ & $(0.00)$ \\
\hline LR test $^{a)}:$ & 0.00 & 0.00 & 0.00 \\
$H_{0}: b=1^{a)}$ & 0.20 & 0.66 & 0.49 \\
\hline \hline Pooled Estimator & & & \\
average intercept & 0.01 & 0.09 & 0.004 \\
& $(0.64)$ & $(0.00)$ & $(0.85)$ \\
& 0.902 & 0.863 & 1.02 \\
& $(0.00)$ & $(0.00)$ & $(0.00)$ \\
\hline$H_{0}: b=1^{a)}$ & 0.00 & 0.00 & 0.00 \\
& 0.04 & 0.00 & 0.71 \\
\hline \hline
\end{tabular}

Notes: Numbers in parentheses represent $p$-values for statistical significance.

a) Test results represented in $p$-values.

the estimated Fama coefficients across the maturity spectrum looks very similar for all time periods considered. Thus, once we take into account the presence of an omitted variable in our regression, not only the maturity related downward bias vanishes but also the trend across the time dimension disappears, which confirms the assumption that the unobserved risk factor is indeed time-varying.

Estimating equation (11) also yields consistent estimates of the coefficient $w_{m}$. Thus, given that $\gamma_{m} \simeq \widehat{\omega}_{m} \Gamma$, if $b_{m}=1$ we are able to identify the maturity specific loadings of the risk premium up to a scaling factor $\Gamma$. Figures 16 to 18 in the Appendix A plot the factor loadings against the maturity $m$ resulting from the mean group CCE estimator based on the entire data sample running from June 1993 to March 2015 ${ }^{12}$ The figures show that the risk premium loadings increase with increasing maturity. This confirms the suggestion from above: The slope coefficients $\beta_{m}$ of the Fama regression (2) decline with increasing maturity, because the importance of the latent risk factor for the foreign exchange return increases. The figures also suggest that we can approximate the risk premium loadings by a linear-quadratic function of maturity.

$$
g_{m}=\delta_{0}+\delta_{1} m+\delta_{2} m^{2}+u_{m}
$$

with $\delta_{2}<0<\delta_{1}$.

\footnotetext{
${ }^{12}$ The factors and factor loadings estimated by the mean group CCE and pooled CCE look almost identical.
} 
Table 4 reports the results of OLS estimates of equation (12) for all three currencies. It shows that the linear-quadratic function indeed fits the risk premium loadings extremely well. The coefficients on the linear and the quadratic maturity are almost identical for all three currencies.

Table 4: Factor Loadings

\begin{tabular}{lrrr}
\hline \hline & US $\$ / D M$ & US $\$ /$ Yen & US $\$ /$ Pound \\
\hline$\delta_{0}$ & 0.042 & 0.021 & -0.042 \\
& $(0.00)$ & $(0.00)$ & $(0.00)$ \\
$\delta_{1}$ & 0.023 & 0.023 & 0.024 \\
& $(0.00)$ & $(0.00)$ & $(0.00)$ \\
$\delta_{2}$ & -0.0001 & -0.0001 & -0.0001 \\
& $(0.00)$ & $(0.00)$ & $(0.00)$ \\
\hline$R^{2}$ & 0.99 & 0.99 & 0.98 \\
\hline \hline Notes: & $p$-values represented in parenthe- \\
sis. & \multicolumn{3}{l}{}
\end{tabular}

To summarize, we have shown that we can characterize the term structure of daily foreign exchange returns by the corresponding futures premium and a latent, futures-contract specific risk factor. The main results from this section are two-fold. First, the risk premium loadings can be characterized by a simple, linear-quadratic function, a result which is reminiscent of the finding of Cochrane \& Piazzesi (2005) for the term structure of interest rates. Second, taking into account the latent risk factor and the bias it causes in in the Fama regression, the slope coefficients on the futures premium are positive and not significantly different from the hypothesized value of one.

\section{The determinants of the latent risk factor}

Figures 19 to 21 show the latent risk factors $\widehat{p}_{k}$ estimated for the three currencies using the modified CCE estimator on futures contracts that settle between June 1993 and March 2015. Recall that these currency risk factors are identified up to a scaling factor. However, since we are interested in analyzing the driving forces of the unobserved factors and less so in their levels, this identification problem can be ignored. The figures shows that the latent risk factors extracted for all three currencies show a high degree of volatility and no specific pattern is detectable at first glance. The correlation between the US\$/Yen risk factor and the US\$/Pound risk factor is 0.13 , the correlation between the US\$/Yen risk factor and the US\$/DM(Euro) risk factor is 0.37 , while the correlation between the US\$/Pound and the US\$/DM(Euro) risk factors is 0.65. Thus, market fluctuations seem to be more interdependent in European markets than between European and Asian markets. 
We first confirm the hypothesis that the rejection of the EH is caused by an omitted variable bias. As pointed out by Fama (1984), a necessary condition for the appearance of the FPP is that the risk variable is negatively correlated with the futures premium $x_{m k}$. Under this premise, omitting the risk factor from the regressions will cause a negative bias on the estimated slope coefficients $\beta_{m}$. Similarly, a slope coefficient significantly larger than one would require that the latent risk factor is positively correlated with the futures premium $x_{m k}$. To test, whether these conditions hold, we calculate a moving-window correlation between the average futures premium for each contract $k$ and the identified scaled risk variable, $\bar{\gamma} p_{k}$, again for a 44 quarters fixed window. The results are shown in Figures 22 to 24 together with the rolling window estimates of the Fama coefficient estimated for the six-months maturity ( $m=$ 126). For all three currencies, we confirm a very close relationship between the estimated Fama coefficient $\beta_{m}$ and the correlation between our extracted risk factors and the average futures premium the maturity spectrum for each contract. In the $90 \mathrm{~s}$, the correlation is generally negative, which explains the strong downward bias of the Fama coefficient in that period. With exception of the Yen futures contracts, this correlation shows an upward trend over time and becomes positive, which explains our finding that the appearance of the FFP is less pronounced when we concentrate on later time periods. For US $\$ /$ Pound futures contracts this sign switch happens at the time window December 1998to September 2009, for US \$ DM(Euros) and US\$/Yen futures contracts a bit later at the time window March 2001 to December 2011 and June 2002 to March 2013, respectively. Thus, the correlation pattern between the extracted factor variable and the average futures premia explain the one time positive and another time negative slope coefficient caused by an omitted variable bias.

To explore the determinants of the currency risk factors contained in futures rates, we analyze the correlation between the extracted factors and several conventional measures of country-specific and global economic and financial market risk. We follow Lustig et al. (2014) and consider global financial market volatility as a proxy for the global risk factor. Specifically, global financial market volatility is measured by the historical (20 days rolling window) volatility of the world stock index (HVstock). Similar as Sarno et al. (2012) we multiply these variables with the sign of the yield differential between the two respective countries. The yield differential is measured by the difference between the US and foreign 2-year government bond 13 By this we assume that in times of global market uncertainty, investors demand higher risk premia on high yield currencies while they accept lower or even negative risk premia on low yield currencies. This follows from the finding by Bansal (1997) and Baillie \& Kilic (2006), who show that the sign of the interest differential influences significantly the bias in the Fama regression coefficient. This also takes into account the hypothesis of Lustig \& Verdelhan (2007), who argues that returns in currency markets are

\footnotetext{
${ }^{13}$ With foreign we mean here Germany or EMU after the introduction of the Euro, UK, and Japan.
} 
related to the sign of the interest differential between the two respective countries. For low interest rate countries with negative interest differentials excess returns are usually negative, for high interest rate currencies with positive interest differentials excess returns are usually positive. All signed variables are indicated by the lower case ' $\mathrm{s}$ ' in front of the variable.

Lustig \& Verdelhan (2007) and Lustig et al. (2014) suggest that the risk premium on US exchange rates is counter-cyclical to the business cycle of the US economy. For this reason, we use the annual growth rate of the US industrial production as additional regressor $\Delta$ IP US). Burnside et al. (2011) show that primarily monetary variables have a significant impact on risk factors in currency markets. We therefore follow Sarno et al. (2012) and control for the annual growth of narrow money supply M2 $(\Delta M 2)$ and the change in the 'observable fundamentals' defined as the country differential in money supply growth minus the country differential in GDP growth (Fundamental). According to exchange rate theory, the relationship between currency excess returns and both monetary variables is expected to be positive.

Clarida et al. (2009) document a significant co-movement between currency risk premia and the 'level' and 'slope' factors that drive bond yields in the respective countries comprising the currency pair. They argue that the level factor is a proxy for persistent movements in real interest rates and/or inflation, which leads to an appreciation of the nominal exchange rate. Thus, an increase in the 'level' factor in the high interest rate country relative to that of the low interest rate country should be positively correlated with carry trade returns or currency risk premia. The 'slope' factor, in contrast, can be regarded as a proxy for the stance of the economy, with the yield curve getting steeper during an expected economic downswing and flatter in an expected economic boom. An increase in the slope factor in the high interest rate country relative to the slope factor in the low interest rate country should, hence, be associated with a reduction in the currency risk premium. We account for the 'level' factor by measuring the growth differential of the ten year US and foreign government bond yield multiplied again with the sign of the yield differential between the two respective countries (sLevel). The 'slope' factor is measured by the relative change in the term spread (10 year minus two year treasury yield) in the high yield currency country relative to low yield currency (sSlope). Moreover, we also add the difference in the 10-year government bond yield between the two respective countries to the set of regressors to see whether we can confirm the finding by Bansal (1997) and Baillie \& Kilic (2006) that the size of the interest differential influences significantly the bias in the Fama regression coefficient (YieldDiff).

Lustig \& Verdelhan (2007) observe that high interest rate currencies depreciate on average when domestic consumption growth is low, while low interest rate currencies appreciate under the same conditions. Their explanation for this finding is that low interest rate curren- 
cies provide domestic investors with a hedge against aggregate domestic consumption growth risk. In line with this argument, we add US consumption growth calculated as log change of total real private consumption per capita multiplied again by the sign of the interest differential of the two respective countries ( $s \Delta$ Consum). We suggest a negative relationship between signed consumption growth and our latent risk factor. And finally, Lustig et al. (2014) show that dollar returns and carry trade risk premia are closely linked to aggregate consumption growth volatility. Similar as Lustig et al. (2014) we measure consumption growth volatility by the 36-months standard deviation of monthly growth rates of total US consumption of non-durable goods (sConsVola). If the time variation in the currency risk premia is due to the time-varying consumption uncertainty, we would expect a negative relationship between the signed consumption volatility measure and our extracted risk factor ${ }^{14}$

Finally, we add year dummies to the regression to capture time fixed effects that are not captured by our explanatory variables. To safe degrees of freedom, we only keep the year dummies that turn out to be significant. That is for all three currencies a dummy for the year 2015 .

All macroeconomic and financial variables are timed at time $t$, the quarter, in which the futures contracts actually expire. The rational for this is that investors price futures prices and risk premia according the macroeconomic and financial environment that they expect to prevail at maturity.

Table 5 shows the estimation result when regressing our extracted latent risk factor on the above listed potential determinants for each currency pair separately ${ }^{15}$ Column (2) differs from (1) in that we drop the variable Fundamental, which is closely related to broad money growth $(\Delta M 2){ }^{16}$ With our selected variables we are able to explain around one third of the variation of the extracted latent risk factor. This supports the hypothesis that a latent currency risk premium drives the appearance of the FFP as suggested by Fama (1984).

In general, we confirm the finding by Lustig et al. (2014) that the currency risk premium is affected by global risk factors. The volatility of the world stock index is highly significant and positive throughout all regressions. Moreover, for all three currencies, we find that the latent risk premium is negatively related to growth in US industrial production. This confirms the result of Sarno et al. (2012) that the currency risk premium is counter-cyclical to the US economy.

We find that the currency risk premium contained in US\$/DM(Euro) and US\$/Pound

${ }^{14}$ Lustig et al. (2014) use in addition the conditional volatility of US inflation. However, this variable turns out to be highly collinear with the volatility of US aggregate consumption volatility.

${ }^{15}$ We have tested for equality of estimated regression coefficients across our three currency pairs. We have to reject the Null Hypothesis of poolability of our data at all reasonable significance levels. This is why we refrain from using a panel estimation approach.

${ }^{16}$ The computed variance inflation factor (VIF)suggest that none of regressions suffers from multicollinearity. Moreover, the Durbin Watson tests cannot rejected the null hypothesis of no serial correlation in the residuals. 
Table 5: Determinants of Currency Risk Premia

\begin{tabular}{|c|c|c|c|c|c|c|}
\hline \multirow[t]{2}{*}{ Variable } & \multicolumn{2}{|c|}{ DM/Euro } & \multicolumn{2}{|c|}{ Pound } & \multicolumn{2}{|c|}{ Yen } \\
\hline & (1) & $(2)$ & (1) & $(2)$ & (1) & $(2)$ \\
\hline sHVstock & $0.10^{* *}$ & $0.10^{* *}$ & $0.19^{* * *}$ & $0.17^{* * *}$ & $0.47^{* * *}$ & $0.48^{* * *}$ \\
\hline$\Delta \mathrm{IP}$ & -0.24 & $-0.26^{*}$ & $-0.33^{* *}$ & $-0.31^{*}$ & $-0.47^{* *}$ & $-0.48^{* *}$ \\
\hline Fundamental & 0.08 & & 0.21 & & -0.17 & \\
\hline$\Delta \mathrm{M} 2$ & -0.17 & -0.09 & -0.02 & 0.2 & $-0.86^{* *}$ & $-0.96^{* * *}$ \\
\hline sSlope & 0.47 & 0.32 & 0.38 & 0.31 & 0.81 & 0.73 \\
\hline sLevel & 1.09 & 0.82 & -0.24 & -0.32 & 1.46 & 1.6 \\
\hline $\mathrm{s} \Delta$ Consum & $-0.68^{* *}$ & $-0.72^{* *}$ & $-1.43^{* * *}$ & $-1.35^{* * *}$ & 1.59 & $1.76^{*}$ \\
\hline sConsVola & -0.01 & -0.01 & 0.00 & 0.00 & $-0.06^{* *}$ & $-0.06^{* *}$ \\
\hline YieldDiff & $-2.69^{* *}$ & $-2.51^{* *}$ & -0.67 & -0.67 & -0.42 & -0.41 \\
\hline d2015 & $-9.24^{* * *}$ & $-9.49^{* * *}$ & $-5.27^{* * *}$ & $-4.80^{* * *}$ & -1.82 & -1.42 \\
\hline Constant & 2.91 & 2.54 & 1.72 & 0.11 & -1.28 & -1.31 \\
\hline $\mathrm{R}^{2}$ & 0.29 & 0.28 & 0.32 & 0.31 & 0.27 & 0.27 \\
\hline $\mathrm{N}$ & 88 & 88 & 88 & 88 & 88 & 88 \\
\hline
\end{tabular}

Notes: ${ }^{*}$ denotes significance at the $10 \%$ significance level, ${ }^{* *}$ at the $5 \%$ significance level, and ${ }^{* * *}$ at the $1 \%$ significance level.

futures contracts is not related to monetary variables. Only for US\$/Yen futures we find that the extracted risk factor is significantly affected by broad money growth. However, the sign of the estimated coefficient is negative and not - as expected - positive. Thus, if the US experiences large money growth, the currency premium on US Dollar decreases surprisingly. For US\$/DM(Euro) futures contracts we show that the interest differential has a significant effect on the currency premium. For large negative interest differentials between the US and Germany, the risk premium increases significantly. We cannot confirm the finding of Clarida et al. (2009) that the 'slope' or 'level' factor of government bond yields explains the risk currency risk premium. Both variables, sLevel and sSlope, turn out to be highly insignificant in all regressions.

Finally, we estimate for all three currencies a negative and significant coefficient on signed per capita consumption growth, although this effect is only weakly significant in case of the Yen futures contracts. Thus, when US consumption growth decreases the currency risk premium increases for high yield currencies and decreases for low yield currencies. This fits with the observation of Lustig \& Verdelhan (2007), who show that high interest rate currencies depreciate on average when US consumption growth is low, while low interest rate currencies appreciate. Moreover, for US\$/Yen futures contracts we confirm a significant negative link between aggregate consumption volatility and currency risk premia, which is in line with Lustig et al. (2014).

All in all, we find that the latent factors extracted from futures contracts are closely 
linked to economic and financial variables measuring global risk, the US and foreign business cycle and traditional exchange rate fundamentals.

\section{Conclusion}

The forward premium puzzle is the empirical observation that foreign exchange forward premia and the realized foreign exchange returns tend to be negatively correlated. In this paper we reconsider the this forward premium puzzle (FFP) using futures instead of forward rates. We investigate the relation between the spot return and the futures premium for the US dollar exchange rates against the Yen, the British Pound, and the German Mark (the Euro after 1999). Futures rates allow us to analyze the relationship at a daily basis with maturity horizons ranging from two days to several months. This yields estimates at a much finer grid than is currently available in the related literature.

Our first result is that the slope coefficient of the conventional 'Fama regression' (1984) depends significantly on the maturity horizon of the futures contract and on the observed time period. For short maturities it is generally positive, and the EH is not rejected by the data. For longer maturity horizons, however, the sign and also size of the slope coefficient depends on the time period covered. A rolling window regression reveals that when focusing on the period prior the global financial crisis, the slope coefficient tends to become negative as the maturity horizon over which expectations are formed increases. However, when we focus on later periods covering the financial crisis, we observe that the FFP is less prominent or even reverses in sign.

Subsequently, we follow the common explanation that the FFP is caused by an omitted variable bias due to the presence of a latent risk premium. We show that if the latent risk premium has a contract specific component, we are able to correct for the possible bias by exploiting the large number of observations from a single futures contract using a modified version of Pesaran's (2006) CCE estimator. We find that running the modified CCE estimator mends for the bias and the estimates are insignificantly different from the hypothesized value of one and no longer depend on the time to maturity and the time period covered.

Our third result is that the latent risk premium extracted from the estimates is closely linked to economic variables that proxy global risk, country individual economic fundamentals and currency risk. These include different measures for general risk aversion of investors, measures for the cyclical stance of the US economy, US private consumption growth, and the interest differential between the two respective countries.

In future research we plan to look into the very long term properties using multi-year horizons of forward rates combined with the shorter term daily observed futures data. On the theoretical side, we plan to investigate which theoretical models support the specification 
of the risk premium that we find in the data. 


\section{References}

Alexius, A. (2003). Uncovered interest parity revisited. Review of International Economics, 9(3), $505-517$.

Backus, D. K., Foresi, S., \& Telmer, C. I. (2001). Affine term structure models and the forward premium anomaly. The Journal of Finance, 56(1), 279-304.

Baillie, R. T. \& Kilic, R. (2006). Do asymmetric and nonlinear adjustments explain the forward premium anomaly? Journal of International Money and Finance, 25(1), 22-47.

Bansal, R. (1997). An exploration of the forward premium puzzle in currency markets. Review of Financial Studies, 10(2), 369-403.

Beck, N. \& Kratz, J. (1995). What to do (and not to do) with times-series-cross-section data. American Political Science Review, 89(3), 634-647.

Burnside, C., Eichenbaum, M., Kleshchelski, I., \& Rebelo, S. (2011). Do peso problems explain the returns to the carry trade? Review of Financial Studies, 24(3), 853-891.

Chaboud, A. P. \& Wright, J. H. (2005). Uncovered interest parity, it works, but not for long. Journal of International Economics, 66(2), 349-362.

Chang, C. \& Chang, J. (1990). Forward and future prices: Evidence from the foreign exchange markets. Journal of Finance, 45(4), 1333-1335.

Chinn, M. D. \& Meredith, G. (2004). Monetary policy and long horizon uncovered interest parity. IMF Staff Papers 51, International Monetary Fund.

Clarida, R. H., Davis, J. M., \& Pedersen, N. (2009). Currency carry trade regimes: Beyond the Fama regression. Journal of International Money and Finance, 28(8), 1375-1389.

Cochrane, J. H. \& Piazzesi, M. (2005). Bond risk premia. American Economic Review, 95(1), $138-160$.

Cornell, B. \& Reinganum, M. (1981). Forward and future prices: Evidence from the foreign exchange markets. Journal of Finance, 36(5), 1035-1046.

Ding, L. (2006). The disappearance of the forward premium puzzle in short horizons. Technical report, mimeo.

Ding, L. \& Ma, J. (2011). The forward premium puzzle: Beyond negative beta. Technical report, mimeo.

Ding, L. \& To, L. (2010). The forward premium puzzle across maturities. Economics Bulletin, 30(2), 1113-1119. 
Engel, C. (2016). Exchange rates, interest rates, and the risk premium. American Economic Review, $106(2), 436-474$.

Fama, E. F. (1984). Forward and spot exchange rates. Journal of Monetary Economics, 14(3), $319-338$.

Fama, E. F. \& Bliss, R. R. (1987). The information in long-maturity forward rates. The American Economic Review, 77(4), 680-692.

Froot, K. A. \& Frankel, J. A. (1989). Forward discount bias: Is it an exchange risk premium". The Quarterly Journal of Economics, 104(1), 139-161.

Hodrick, R. J. \& Srivastava, S. (1987). Foreign currency futures. Journal of International Economics, 22(1-2), 1-24.

Hsieh, D. A. (1984). Tests of rational expectations and no risk premium in forward exchange markets. Journal of International Economics, 17(1-2), 173-184.

Lustig, H., Roussanov, N., \& Verdelhan, A. (2014). Countercyclical currency risk premia. Journal of Financial Economics, 111(3), 527-553.

Lustig, H. \& Verdelhan, A. (2007). The cross section of foreign currency risk premia and consumption growth risk. American Economic Review, 97(1), 89-117.

Pesaran, H. (2006). Estimation and inference in large heterogeneous panels with a multifactor error structure. Econometrica, 74(4), 967-1012.

Sarno, L., Schneider, P., \& Wagner, C. (2012). Properties of foreign exchange risk premiums. Journal of Financial Economics, 105(2), 279-310.

Thornton, D. L. (2007). Resolving the unbiasedness and forward premium puzzles. Working Papers 2007-014A, Federal Reserve Bank of St. Louis.

Yang, K. \& Shintani, M. (2006). Does the prediction horizon matter for the forward premium anomaly? Evidence from panel data. Economic Letters, 93(2), 255-260. 


\section{A Appendix A. proof of Proposition 2.}

In the main text we claim the following:

Proposition 2. Suppose we run the multiple regression (11), given the stated assumptions, then as $M \rightarrow \infty$ and $K \rightarrow \infty$ the coefficient estimates are:

$$
\widehat{b}_{m} \stackrel{p}{\rightarrow} b_{m}
$$

from (5), and:

$$
\widehat{\omega}_{m} \stackrel{p}{\rightarrow} \frac{\gamma_{m}}{A-a+\Gamma}
$$

Moreover, in the case that $b_{m}=1$, then:

$$
\widehat{\omega}_{m} \stackrel{p}{\rightarrow} \gamma_{m} / \Gamma
$$

Proof. We have to show consistency of the modified CCE estimators. The proof is very similar to Pesaran (2006)'s proof of consistency for the standard CCE. The theoretical model reads:

$$
\begin{aligned}
y_{m, k} & =b_{m} x_{m, k}+\gamma_{m} p_{k}+e_{m, k} \\
& =b_{m} a_{m} p_{k}+\gamma_{m} p_{k}+e_{m, k}+b_{m} \mu_{m, k} .
\end{aligned}
$$

since it is assumed that the futures premium is linearly related to the risk premium

$$
x_{m, k}=a_{m} p_{k}+\mu_{m, k} .
$$

Recall the definitions of the shorthand for sums of the (weighted) coefficients in $(13)$ :

$$
a=\frac{1}{M} \sum_{m}^{M} a_{m} ; A=\frac{1}{M} \sum_{m}^{M} b_{m} a_{m} ; \Gamma=\frac{1}{M} \sum_{m}^{M} \gamma_{m}
$$

and the normality assumptions $p_{k} \sim N\left(p, v_{p}^{2}\right), \mu_{m, k} \sim N\left(0, \sigma_{\mu}^{2}\right)$ and $e_{m, k} \sim N\left(0, \sigma_{e}^{2}\right)$ from Assumption 1.

We run the following multiple regression:

$$
y_{m, k}=b_{m} x_{m, k}+\omega_{m} w_{k}+\eta_{m, k},
$$


where

$$
\begin{aligned}
w_{k} \equiv & \frac{1}{M} \sum_{m}^{M} y_{m, k}-\frac{1}{M} \sum_{m}^{M} x_{m, k} \\
= & (A-a+\Gamma) p_{k}+\frac{1}{M} \sum_{m}^{M}\left(e_{m, k}+\left(b_{m}-1\right) \mu_{m, k}\right) \\
\sim & (A-a+\Gamma) N\left(p, v_{p}^{2}\right)+N\left(0, \sigma_{e}^{2} / M\right) \\
& +N\left(0, \frac{1}{M^{2}} \sigma_{\mu}^{2} \sum_{m}^{M}\left(b_{m}-1\right)^{2}\right) .
\end{aligned}
$$

In addition to the above, we need the following sums in analyzing the multiple regression:

$$
\begin{aligned}
\frac{1}{K} \sum_{k}^{K} x_{m, k} w_{k}= & \frac{1}{K} \sum_{k}^{K}\left[a_{m} p_{k}+\mu_{m, k}\right]\left[(A-a+\Gamma) p_{k}+\frac{1}{M} \sum_{m}^{M}\left(e_{m, k}+\left(b_{m}-1\right) \mu_{m, k}\right)\right] \\
& =a_{m}(A-a+\Gamma) \frac{1}{K} \sum_{k}^{K} p_{k}^{2}+a_{m} \frac{1}{K M} \sum_{k}^{K} p_{k} \sum_{m}^{M} e_{m, k} \\
& +a_{m} \frac{1}{K M} \sum_{k}^{K} p_{k} \sum_{m}^{M}\left(b_{m}-1\right) \mu_{m, k}+(A-a+\Gamma) \frac{1}{K} \sum_{k}^{K} p_{k} \mu_{m, k} \\
& +\frac{1}{K M} \sum_{k}^{K} \mu_{m, k} \sum_{j}^{M} e_{j, k}+\frac{1}{K M} \sum_{k}^{K} \mu_{m, k} \sum_{j}^{M}\left(b_{j}-1\right) \mu_{j, k} \\
& =a_{m}(A-a+\Gamma) v_{p}^{2}+O_{p}(1 / K)+O_{p}(1 / \sqrt{K M})+O_{p}(1 / M),
\end{aligned}
$$

since $\mu_{m, k}, e_{m, k}$ and $p_{k}$ are independent by assumption. Moreover, we summarize the order terms that are of the same order simply by a single $O$-term. 
The other sum that we need is:

$$
\begin{aligned}
\frac{1}{K} \sum_{k}^{K} w_{k}^{2}= & \frac{1}{K} \sum_{k}^{K}\left[(A-a+\Gamma) p_{k}+\frac{1}{M} \sum_{m}^{M}\left(e_{m, k}+\left(b_{m}-1\right) \mu_{m, k}\right)\right]^{2} \\
= & (A-a+\Gamma)^{2} \frac{1}{K} \sum_{k}^{K} p_{k}^{2} \\
& +2(A-a+\Gamma) \frac{1}{K} \sum_{k}^{K} p_{k} \frac{1}{M} \sum_{m}^{M}\left(e_{m, k}+\left(b_{m}-1\right) \mu_{m, k}\right) \\
& +\frac{1}{K} \sum_{k}^{K} \frac{1}{M^{2}}\left(\sum_{m}^{M}\left(e_{m, k}+\left(b_{m}-1\right) \mu_{m, k}\right)\right)^{2} \\
= & (A-a+\Gamma)^{2} v_{p}^{2}+O_{p}(1 / K)+O_{p}(1 / \sqrt{K M}) \\
& =(A-a+\Gamma)^{2} v_{p}^{2}+O_{p}(1 / \sqrt{K})+O_{p}(1 / \sqrt{K M}) .
\end{aligned}
$$

The multiple regression (14) when applied to (13) gives the CCE coefficient estimates for a particular maturity $m$. The data matrix with the two explanatory variables is $X=$ $\left(x_{m, k} ; w_{k}\right)$. Then:

$$
\begin{aligned}
& \frac{1}{K} X^{T} X \\
= & \left(\begin{array}{cc}
\frac{1}{K} \sum_{k}^{K} x_{m, k}^{2} & \frac{1}{K} \sum_{k}^{K} x_{m, k} w_{k} \\
\frac{1}{K} \sum_{k}^{K} x_{m, k} w_{k} & \frac{1}{K} \sum_{k}^{K} w_{k}^{2}
\end{array}\right) \\
& \stackrel{p}{\rightarrow}\left(\begin{array}{cc}
a_{m}^{2} v_{p}^{2}+\sigma_{\mu}^{2} & a_{m}(A-a+\Gamma) v_{p}^{2} \\
a_{m}(A-a+\Gamma) v_{p}^{2} & (A-a+\Gamma)^{2} v_{p}^{2}
\end{array}\right),
\end{aligned}
$$

if both $M$ and $K$ are large. So we require both $K$ and $M$ to tend to infinity, in no particular order. The benefit of using futures data instead of forwards is that $M$ can be large as well. The inverse of this matrix is:

$$
\begin{aligned}
& \left(\frac{1}{K} X^{T} X\right)^{-1} \stackrel{p}{\rightarrow} \frac{\left(\begin{array}{cc}
(A-a+\Gamma)^{2} v_{p}^{2} & -a_{m}(A-a+\Gamma) v_{p}^{2} \\
-a_{m}(A-a+\Gamma) v_{p}^{2} & a_{m}^{2} v_{p}+\sigma_{\mu}^{2}
\end{array}\right)}{\left[a_{m}^{2} v_{p}^{2}+\sigma_{\mu}^{2}\right](A-a+\Gamma)^{2} v_{p}^{2}-a_{m}^{2}(A-a+\Gamma)^{2} v_{p}^{4}} \\
= & \frac{1}{(A-a+\Gamma)^{2} v_{p}^{2} \sigma_{\mu}^{2}}\left(\begin{array}{cc}
(A-a+\Gamma)^{2} v_{p}^{2} & -a_{m}(A-a+\Gamma) v_{p}^{2} \\
-a_{m}(A-a+\Gamma) v_{p}^{2} & a_{m}^{2} v_{p}^{2}+\sigma_{\mu}^{2}
\end{array}\right) .
\end{aligned}
$$


Furthermore, for large $K$ and $M$ :

$$
\begin{aligned}
\frac{1}{K} X^{T} y= & \left(\begin{array}{c}
\frac{1}{K} \sum_{k}^{K} x_{m, k} y_{m, k} \\
\frac{1}{K} \sum_{k}^{K} w_{m, k} y_{m, k}
\end{array}\right) \\
= & \left(\begin{array}{c}
a_{m}\left(b_{m} a_{m}+\gamma_{m}\right) v_{p}^{2}+b_{m} \sigma_{\mu}^{2}+O_{p}(1 / \sqrt{K}) \\
(A-a+\Gamma)\left(b_{m} a_{m}+\gamma_{m}\right) v_{p}^{2}+O_{p}(1 / \sqrt{K})+O_{p}(1 / \sqrt{K M})
\end{array}\right) \\
& \stackrel{p}{\rightarrow}\left(\begin{array}{c}
a_{m}\left(b_{m} a_{m}+\gamma_{m}\right) v_{p}+b_{m} \sigma_{\mu}^{2} \\
(A-a+\Gamma)\left(b_{m} a_{m}+\gamma_{m}\right) v_{p}^{2}
\end{array}\right)
\end{aligned}
$$

where we use that:

$$
\begin{aligned}
& \frac{1}{K} \sum_{k}^{K} w_{m, k} y_{m, k} \\
= & \frac{1}{K} \sum_{k}^{K}\left[(A-a+\Gamma) p_{k}+\frac{1}{M} \sum_{m}^{M}\left[e_{m, k}+\left(b_{m}-1\right) \mu_{m, k}\right]\right] \times \\
& {\left[\left(b_{m} a_{m}+\gamma_{m}\right) p_{k}+e_{m, k}+b_{m} \mu_{m, k}\right] } \\
= & (A-a+\Gamma)\left(b_{m} a_{m}+\gamma_{m}\right) \frac{1}{K} \sum_{k}^{K} p_{k}^{2}+(A-a+\Gamma) \frac{1}{K} \sum_{k}^{K} p_{k}\left(e_{m, k}+b_{m} \mu_{m, k}\right) \\
& +\left(b_{m} a_{m}+\gamma_{m}\right) \frac{1}{K} \sum_{k}^{K} p_{k} \frac{1}{M} \sum_{j}^{M}\left[e_{m, k}+\left(b_{j}-1\right) \mu_{j, k}\right] \\
& +\frac{1}{K} \sum_{k}^{K}\left(e_{m, k}+b_{m} \mu_{m, k}\right) \frac{1}{M} \sum_{j}^{M}\left[e_{j, k}+\left(b_{j}-1\right) \mu_{j, k}\right] \\
= & (A-a+\Gamma)\left(b_{m} a_{m}+\gamma_{m}\right) v_{p}^{2}+O_{p}(1 / K)+O_{p}(1 / \sqrt{K}) \\
& +O_{p}(1 / \sqrt{K M}) \\
& +O_{p}(1 / K M)+O_{p}(1 / \sqrt{K M}) \\
= & (A-a+\Gamma)\left(b_{m} a_{m}+\gamma_{m}\right) v_{p}^{2}+O_{p}(1 / \sqrt{K})+O_{p}(1 / \sqrt{K M})
\end{aligned}
$$

Finally, we arrive at the coefficient estimates. For large $M$ and $K$

$$
\begin{aligned}
& \left(\begin{array}{c}
\widehat{b}_{m} \\
\widehat{\omega}_{m}
\end{array}\right)=\frac{1}{K}\left(\frac{1}{K} X^{T} X\right)^{-1} X^{T} y \\
& \stackrel{p}{\rightarrow} \frac{1}{(A-a+\Gamma)^{2} v_{p}^{2} \sigma_{\mu}^{2}} \times \\
& \left(\begin{array}{cc}
(A-a+\Gamma)^{2} v_{p}^{2} & -a_{m}(A-a+\Gamma) v_{p}^{2} \\
-a_{m}(A-a+\Gamma) v_{p}^{2} & a_{m}^{2} v_{p}^{2}+\sigma_{\mu}^{2}
\end{array}\right)\left(\begin{array}{c}
a_{m}\left(b_{m} a_{m}+\gamma_{m}\right) v_{p}^{2}+b_{m} \sigma_{\mu}^{2} \\
(A-a+\Gamma)\left(b_{m} a_{m}+\gamma_{m}\right) v_{p}^{2}
\end{array}\right) .
\end{aligned}
$$


Thus:

$$
\begin{aligned}
\widehat{b}_{m} & \stackrel{p}{\rightarrow} \frac{1}{(A-a+\Gamma)^{2} v_{p}^{2} \sigma_{\mu}^{2}} \times \\
& \left\{(A-a+\Gamma)^{2} a_{m}\left(b_{m} a_{m}+\gamma_{m}\right) v_{p}^{4}+(A-a+\Gamma)^{2} v_{p}^{2} b_{m} \sigma_{\mu}^{2}\right. \\
& \left.-a_{m}(A-a+\Gamma)^{2}\left(b_{m} a_{m}+\gamma_{m}\right) v_{p}^{4}\right\} \\
& =\frac{a_{m}\left(b_{m} a_{m}+\gamma_{m}\right) v_{p}^{2}+b_{m} \sigma_{\mu}^{2}-a_{m}\left(b_{m} a_{m}+\gamma_{m}\right) v_{p}^{2}}{\sigma_{\mu}^{2}} \\
& =b_{m} .
\end{aligned}
$$

Regarding the parameter on the constructed regressor, we obtain:

$$
\begin{aligned}
\widehat{\omega}_{m} & \stackrel{p}{\rightarrow} \frac{1}{(A-a+\Gamma)^{2} v_{p}^{2} \sigma_{\mu}^{2}} \times \\
\{ & -a_{m}(A-a+\Gamma) a_{m}\left(b_{m} a_{m}+\gamma_{m}\right) v_{p}^{4}-a_{m}(A-a+\Gamma) v_{p} b_{m} \sigma_{\mu}^{2} \\
& \left.+a_{m}^{2}(A-a+\Gamma)\left(b_{m} a_{m}+\gamma_{m}\right) v_{p}^{4}+\sigma_{\mu}^{2}(A-a+\Gamma)\left(b_{m} a_{m}+\gamma_{m}\right) v_{p}^{2}\right\} \\
& =\frac{-a_{m}^{2}\left(b_{m} a_{m}+\gamma_{m}\right) v_{p}^{2}-a_{m} b_{m} \sigma_{\mu}^{2}+a_{m}^{2}\left(b_{m} a_{m}+\gamma_{m}\right) v_{p}^{2}+\sigma_{\mu}^{2}\left(b_{m} a_{m}+\gamma_{m}\right)}{(A-a+\Gamma) \sigma_{\mu}^{2}} \\
& =\frac{-a_{m} b_{m} \sigma_{\mu}^{2}+\sigma_{\mu}^{2}\left(b_{m} a_{m}+\gamma_{m}\right)}{(A-a+\Gamma) \sigma_{\mu}^{2}} \\
& =\frac{\gamma_{m}}{A-a+\Gamma} .
\end{aligned}
$$

So the coefficient on the constructed regressor recovers the unobserved scaling factor $\gamma_{m}$ of $p_{k}$ per maturity, divided by the averages $A-a+\Gamma$. Also note that under the null of the EH $b_{m}=1$, so that $A-a=0$, and hence:

$$
\widehat{\omega}_{m} \simeq \gamma_{m} / \Gamma
$$

\section{QED}




\section{B Figures}

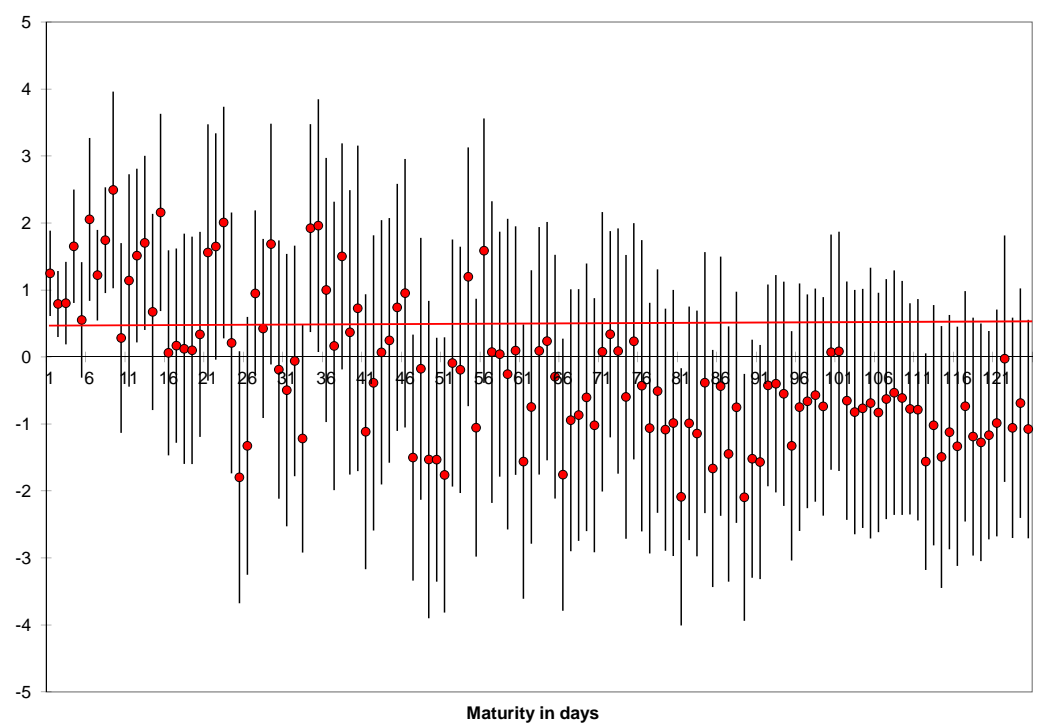

Figure 1: $\beta_{m}, \mathrm{US} \$ / \mathrm{DM}($ Euro) futures contracts - Fama regression

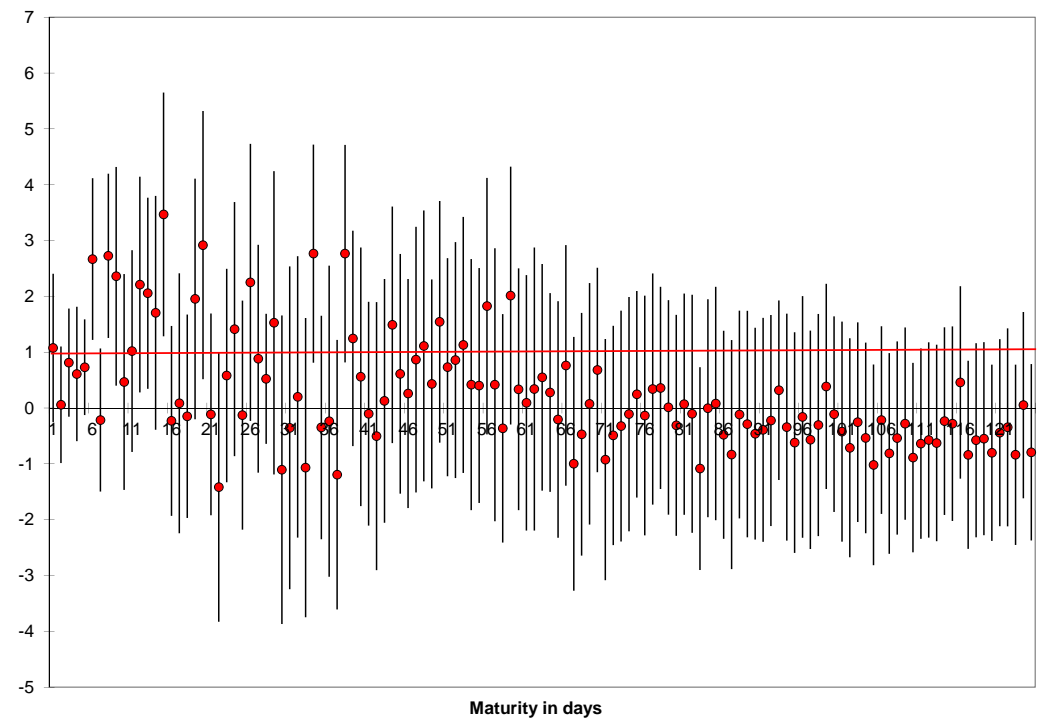

Figure 2: $\widehat{\beta}_{m}$, US\$/Yen futures contracts - Fama regression 


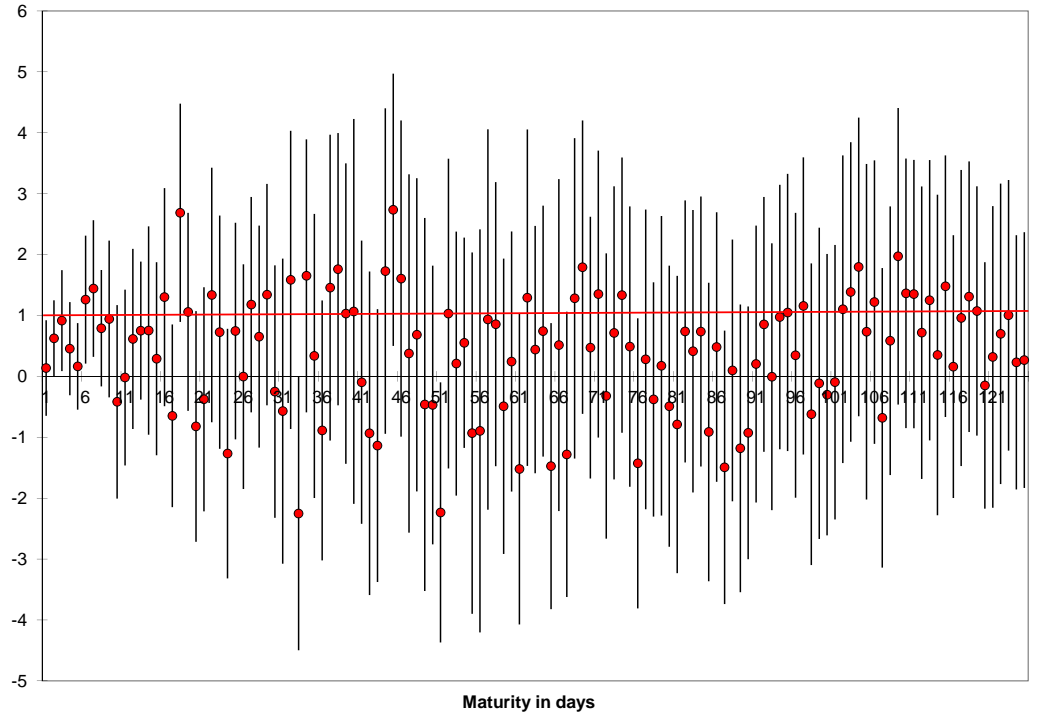

Figure 3: $\widehat{\beta}_{m}, \mathrm{US} \$ /$ Pound futures contracts - Fama regression

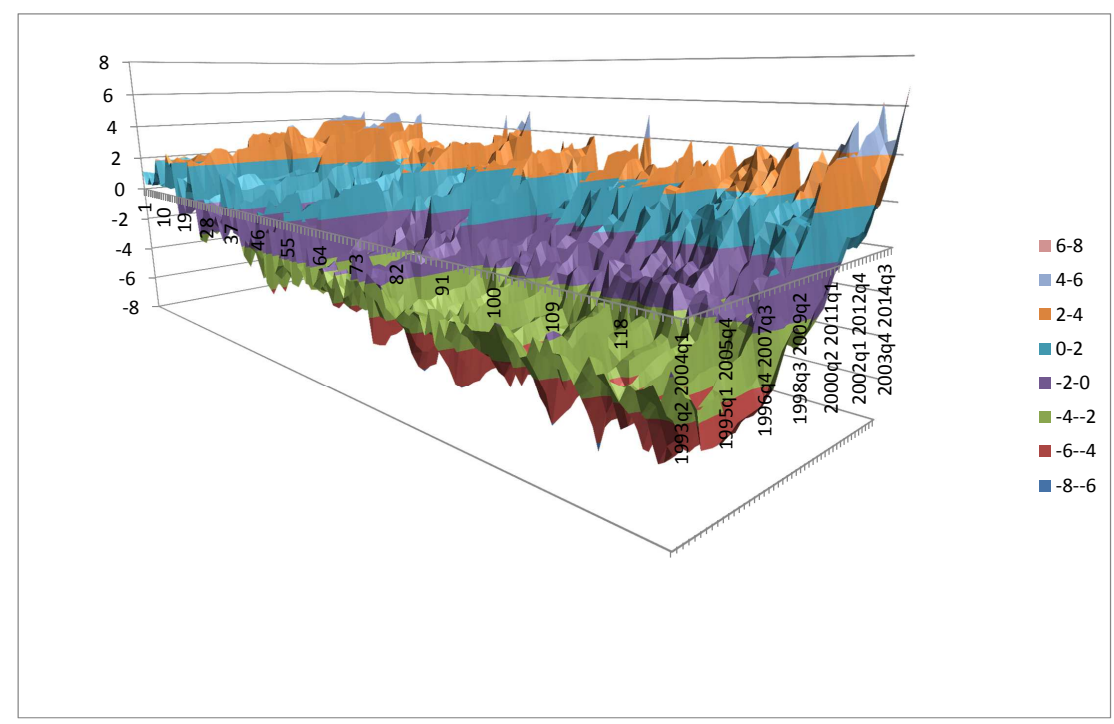

Figure 4: US\$/DM(Euro) futures contracts - Rolling window $\widehat{\beta}_{m}$ estimations estimations for various time periods 


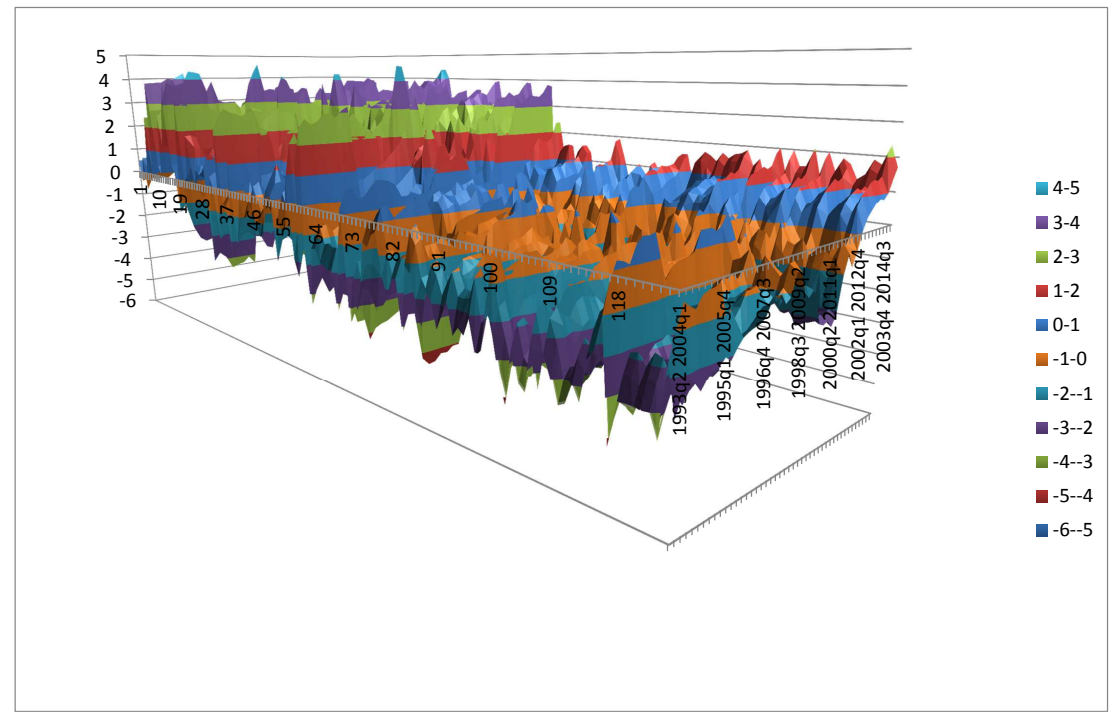

Figure 5: US $\$ /$ Yen futures contracts - Rolling window $\widehat{\beta}_{m}$ estimations for various time periods

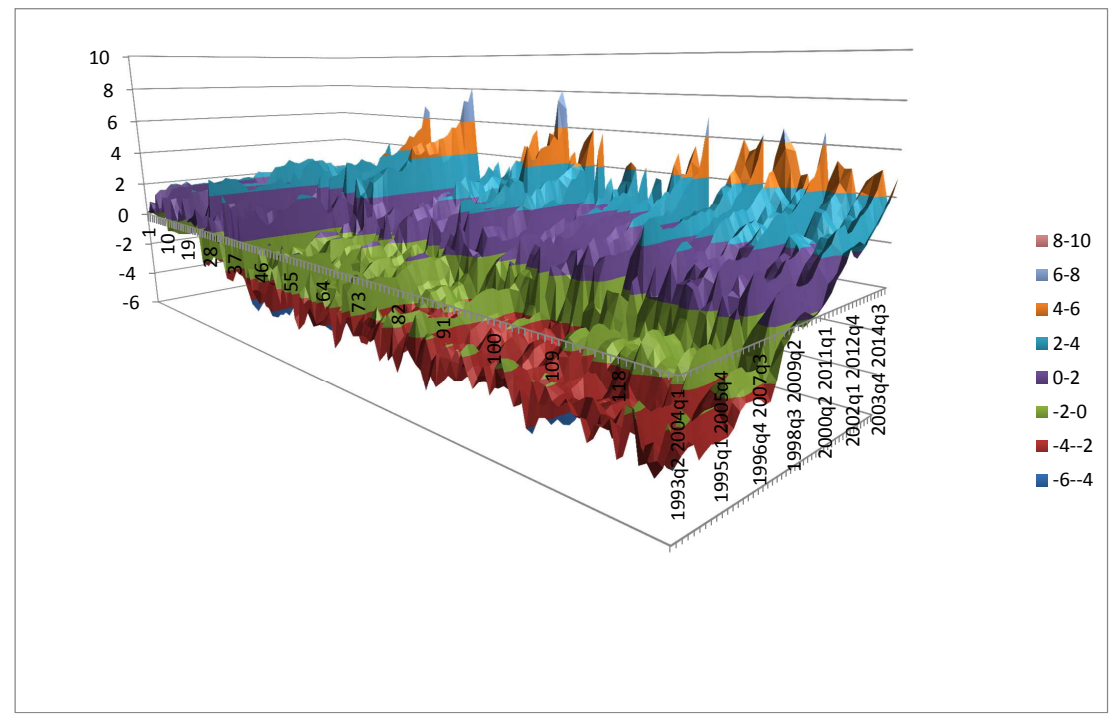

Figure 6: US $\$ /$ Pound futures contracts - Rolling window $\widehat{\beta}_{m}$ estimations for various time periods 


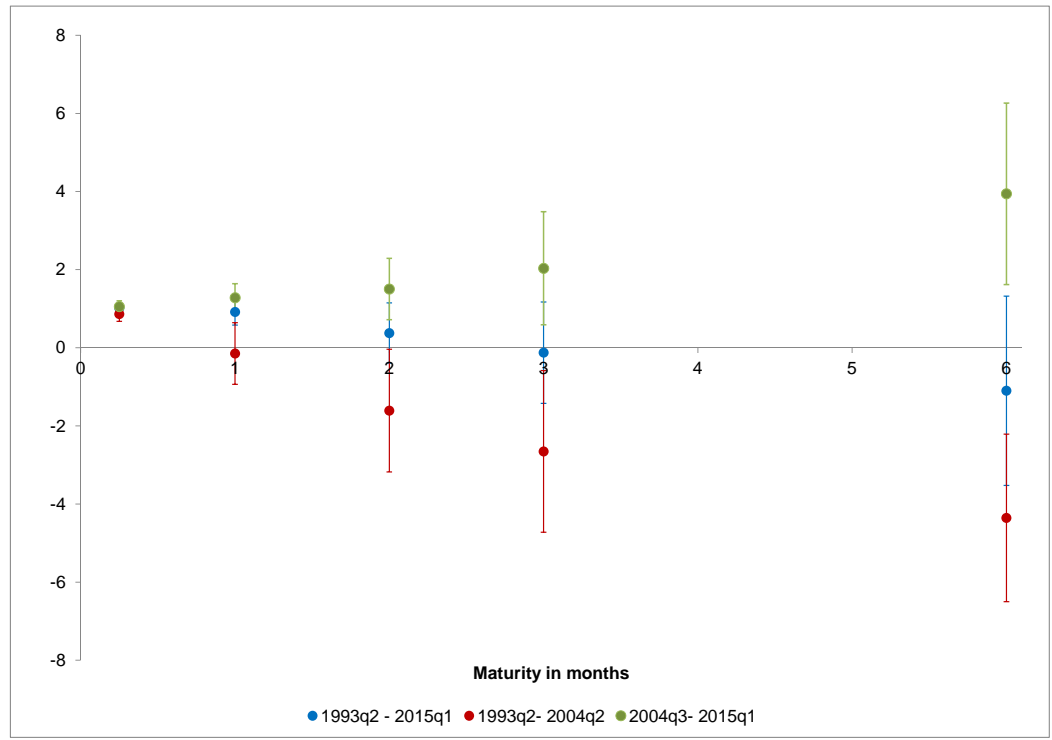

Figure 7: US\$/DM(Euro) forward contracts, $\widehat{\beta}_{m}$ estimations

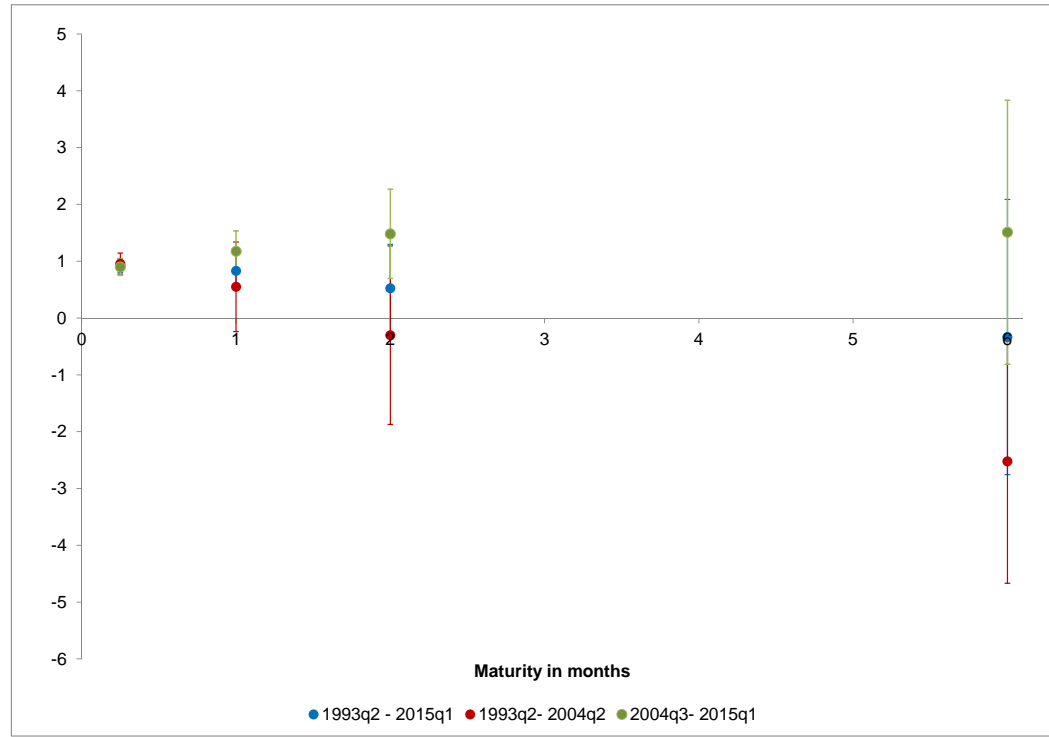

Figure 8: US $\$ /$ Yen forward contracts, $\widehat{\beta}_{m}$ estimations 


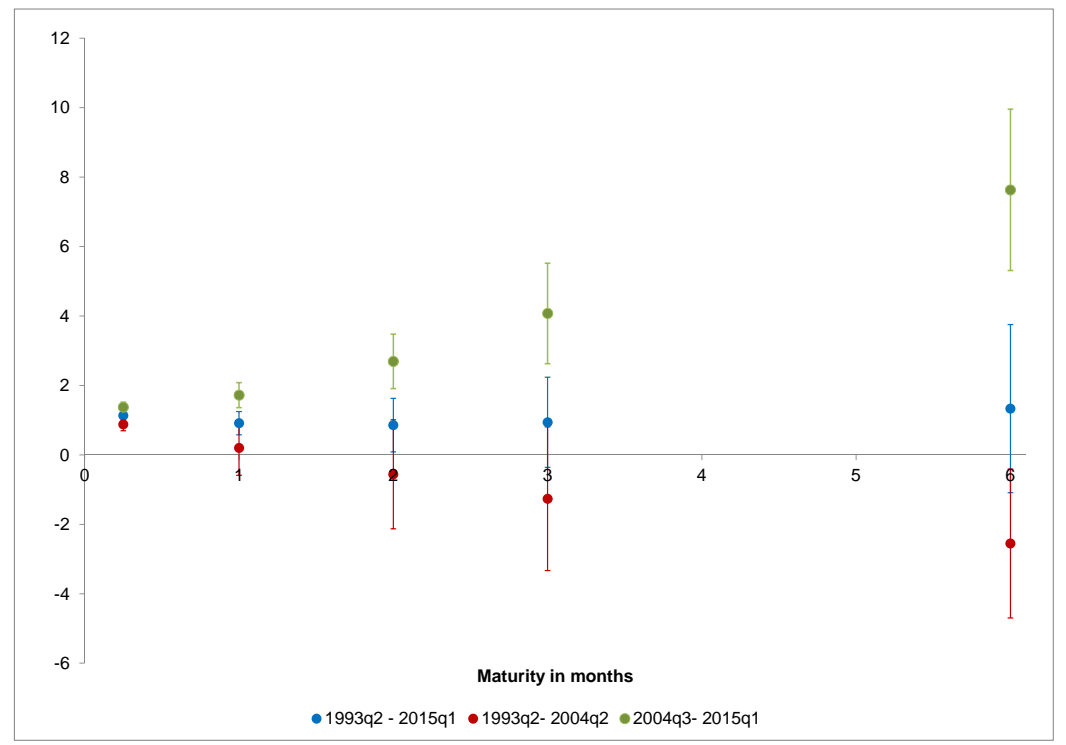

Figure 9: US\$/Pound forward contracts, $\widehat{\beta}_{m}$ estimations

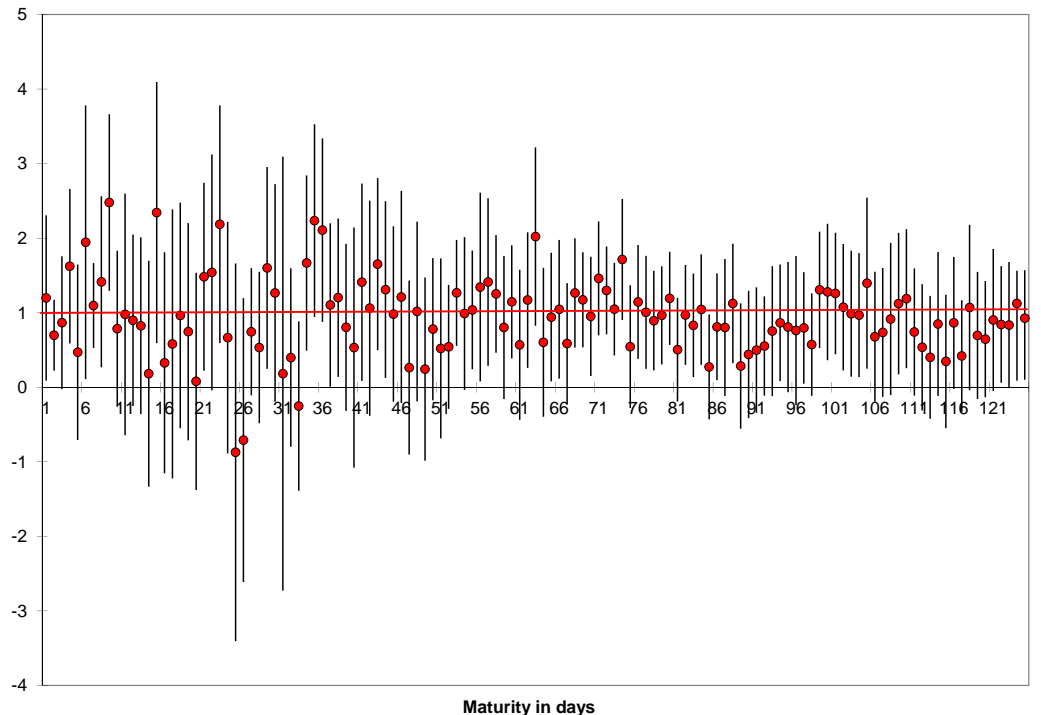

Figure 10: US\$/DM(Euro) futures contracts - CCE $\widehat{b}_{m}$ estimations estimations 


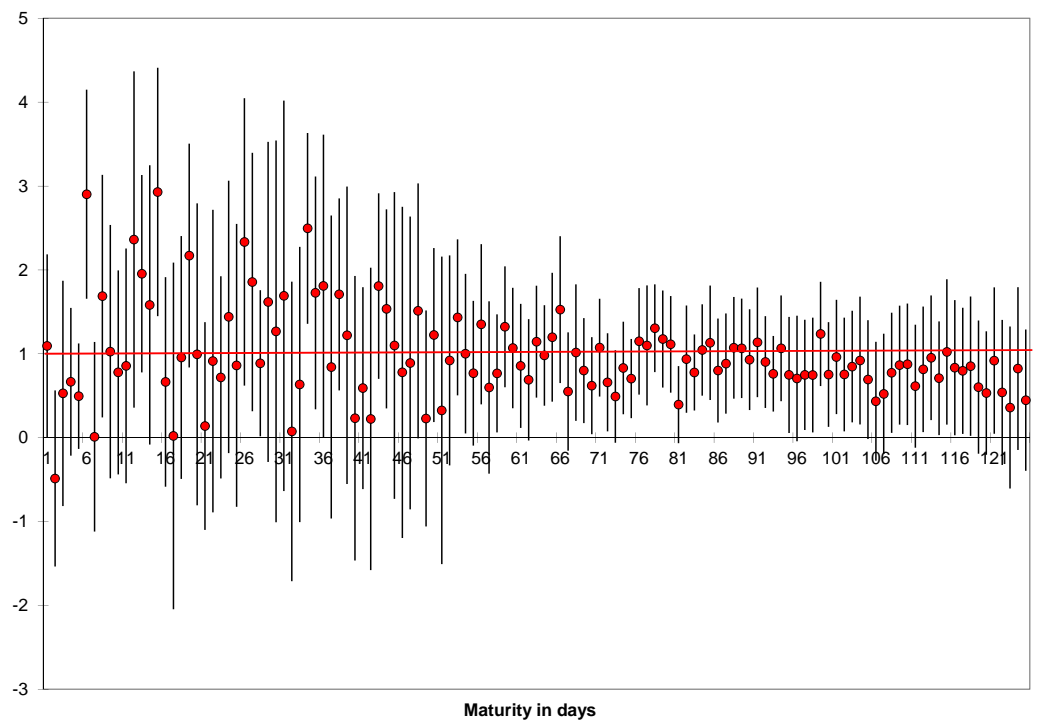

Figure 11: US\$/Yen futures contracts - CCE $\widehat{b}_{m}$ estimations

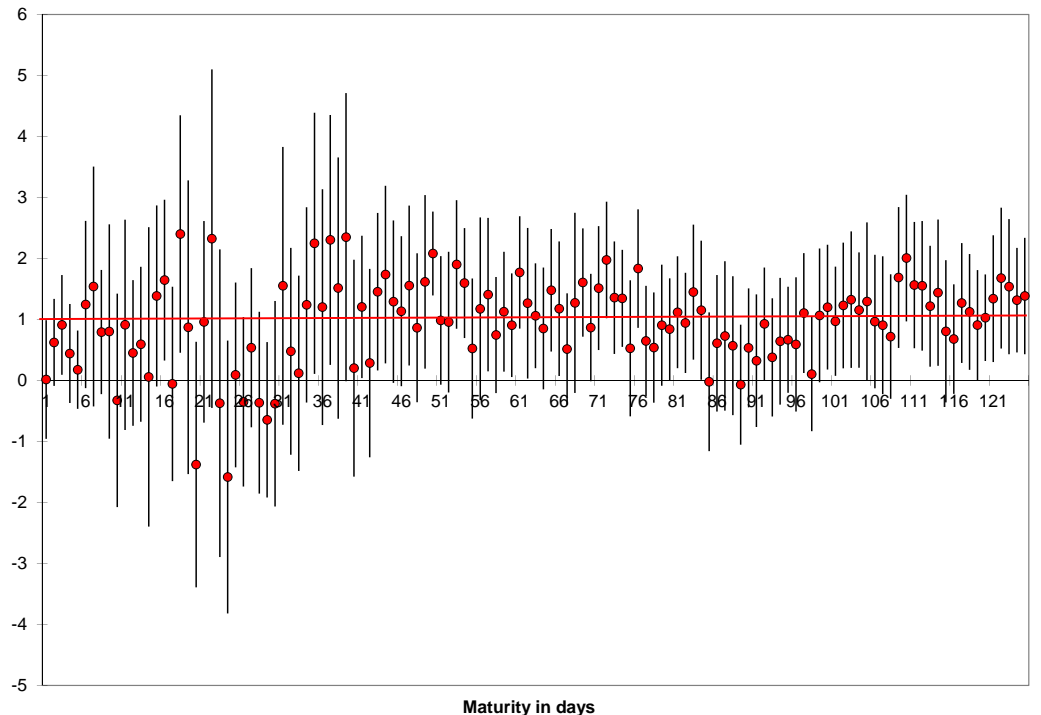

Figure 12: US $\$ /$ Pound futures contracts - CCE $\widehat{b}_{m}$ estimations 


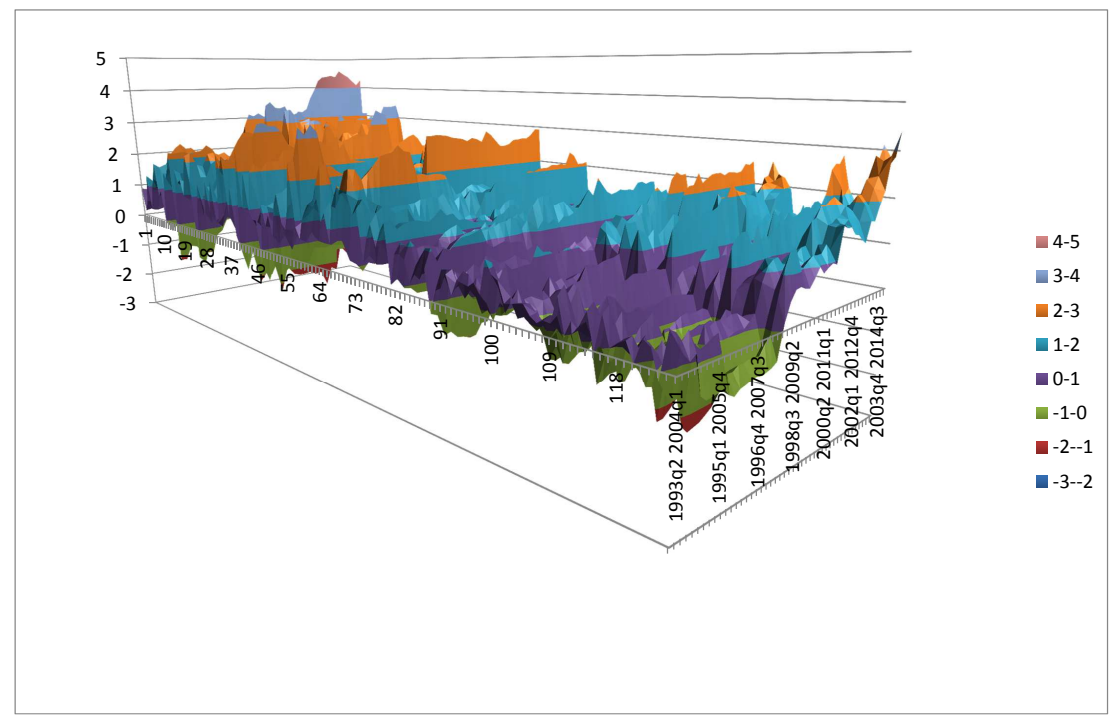

Figure 13: US\$/DM(Euro) futures contracts - Rolling window CCE $b_{m}$ estimations estimations for various time periods

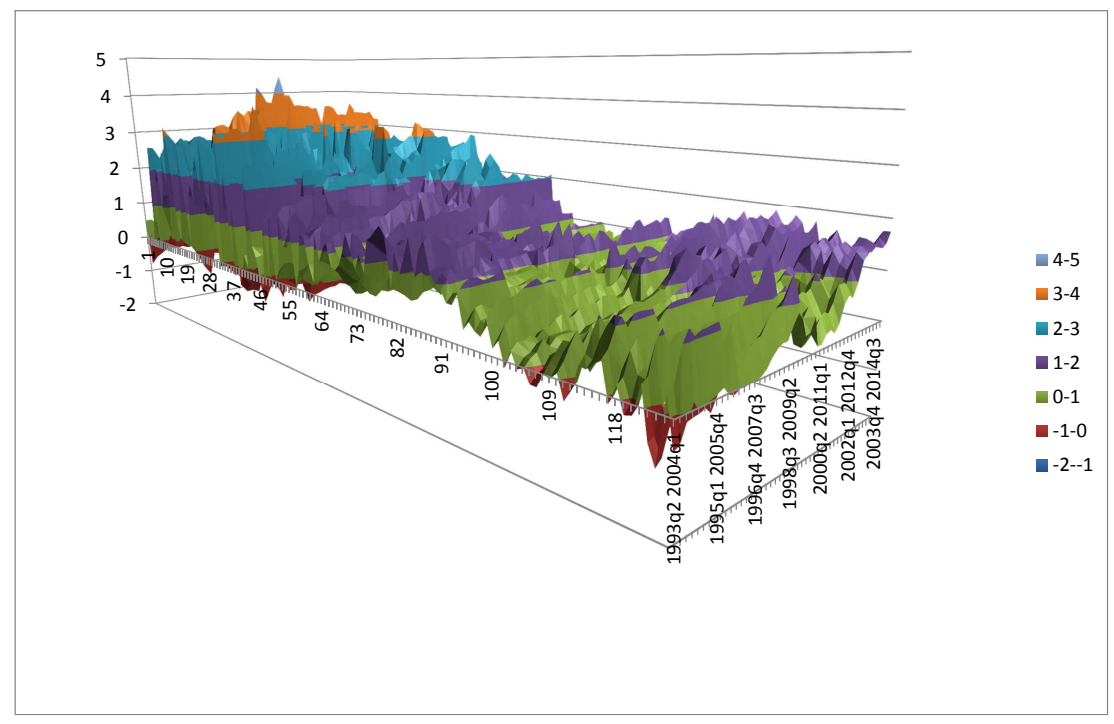

Figure 14: US\$/Yen futures contracts - Rolling window CCE $b_{m}$ estimations for various time periods 


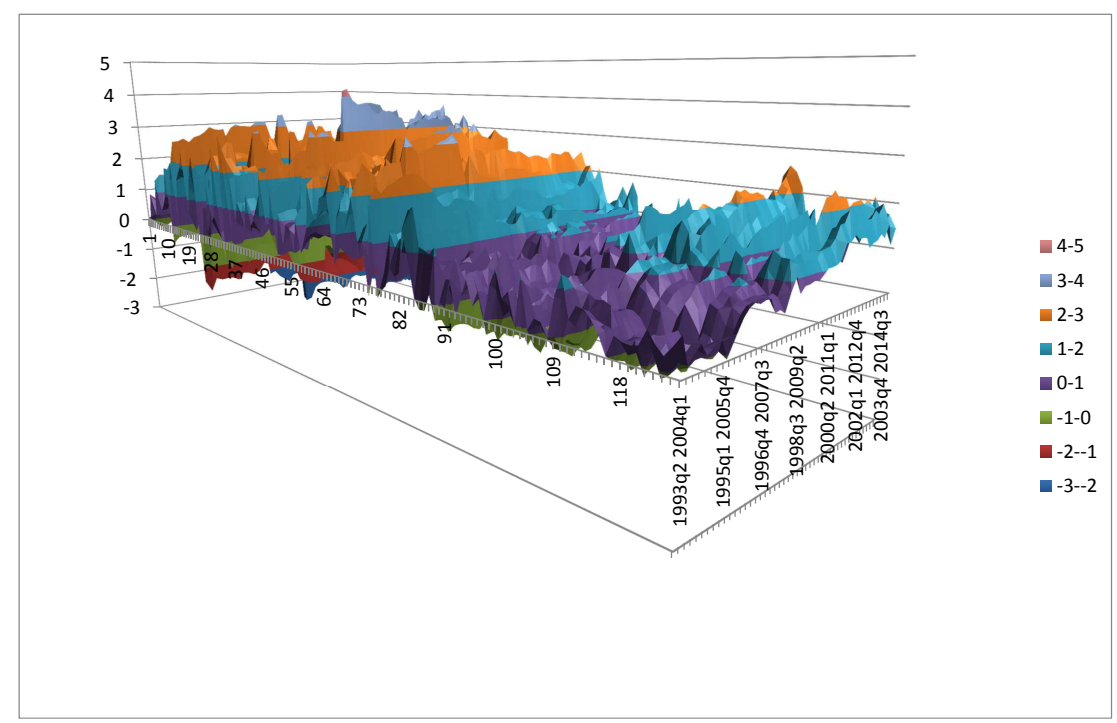

Figure 15: US\$/Pound futures contracts - Rolling window CCE $b_{m}$ estimations for various time periods 


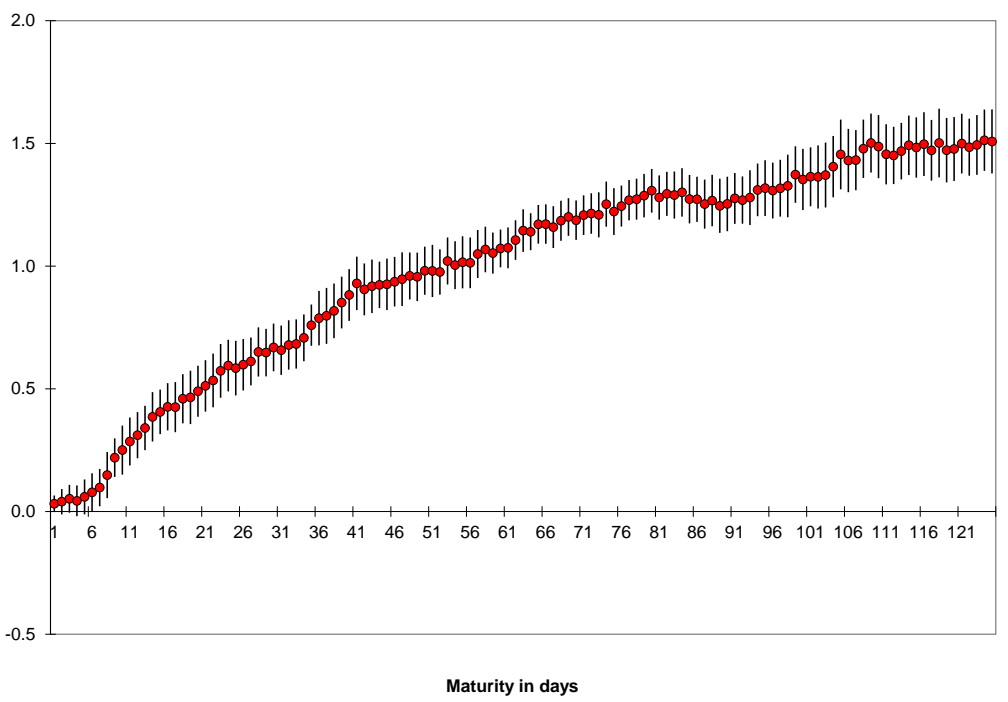

Figure 16: Scaled risk premium loadings across maturity - DM futures contracts

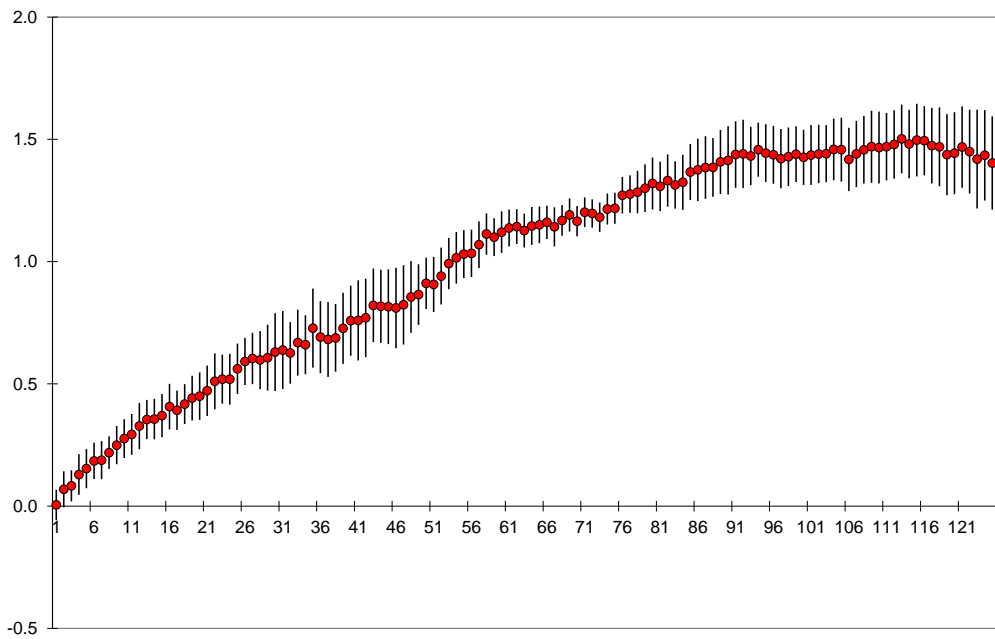

Maturity in days

Figure 17: Scaled risk premium loadings across maturity - Yen futures contracts 


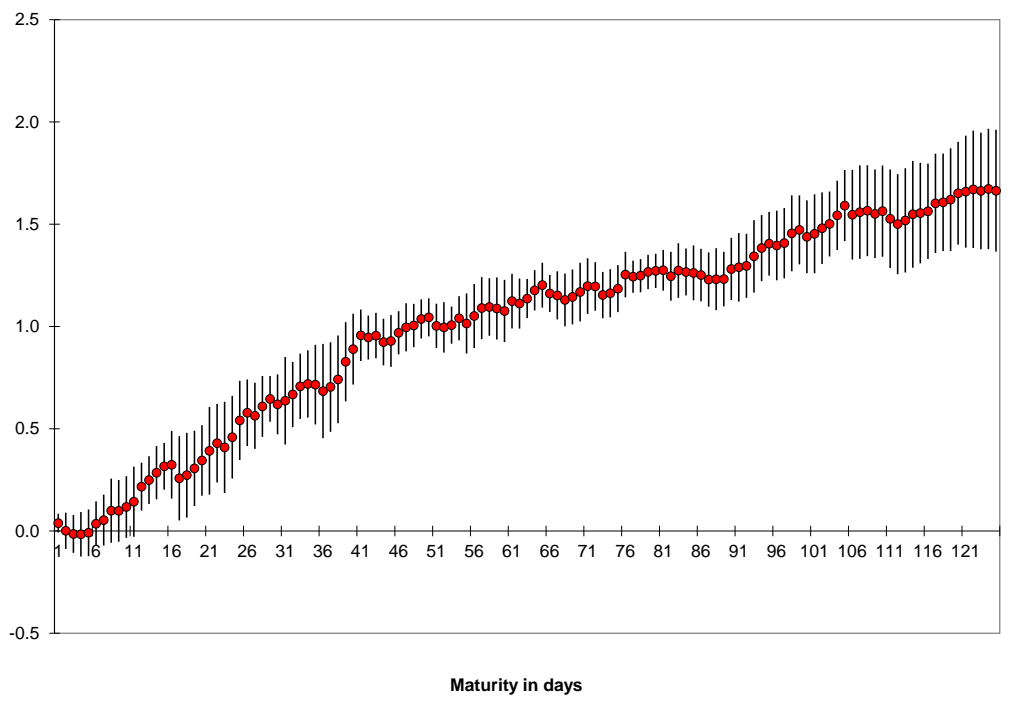

Figure 18: Scaled risk premium loadings across maturity - Pound futures contracts

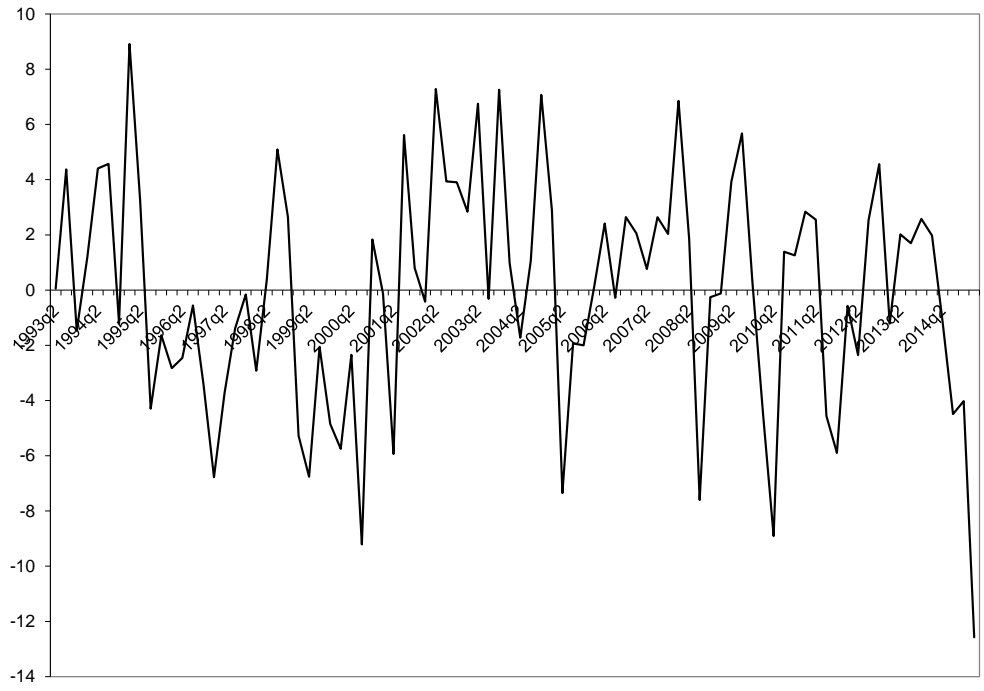

Figure 19: Scaled risk premium across time - DM futures contracts 


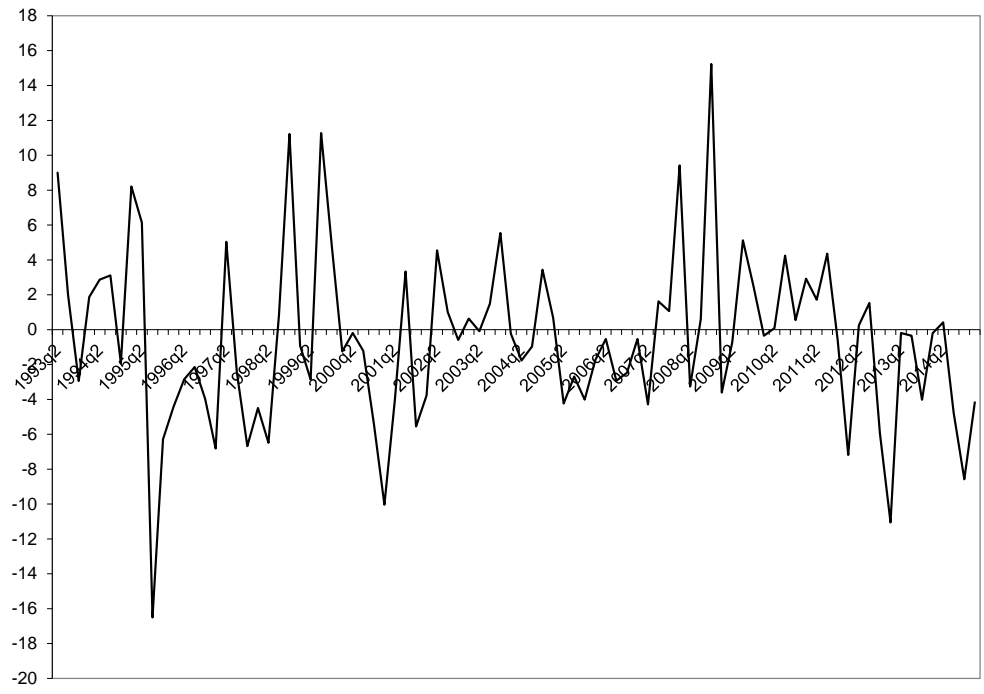

Figure 20: Scaled risk premium across time - Yen futures contracts

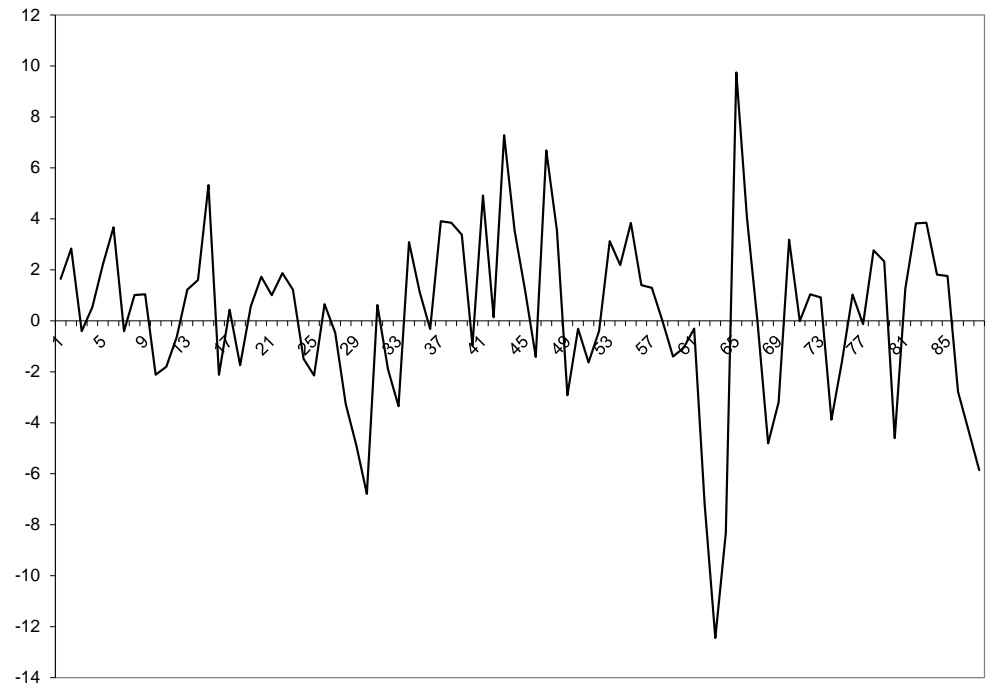

Figure 21: Scaled risk premium across time - Pound futures contracts 


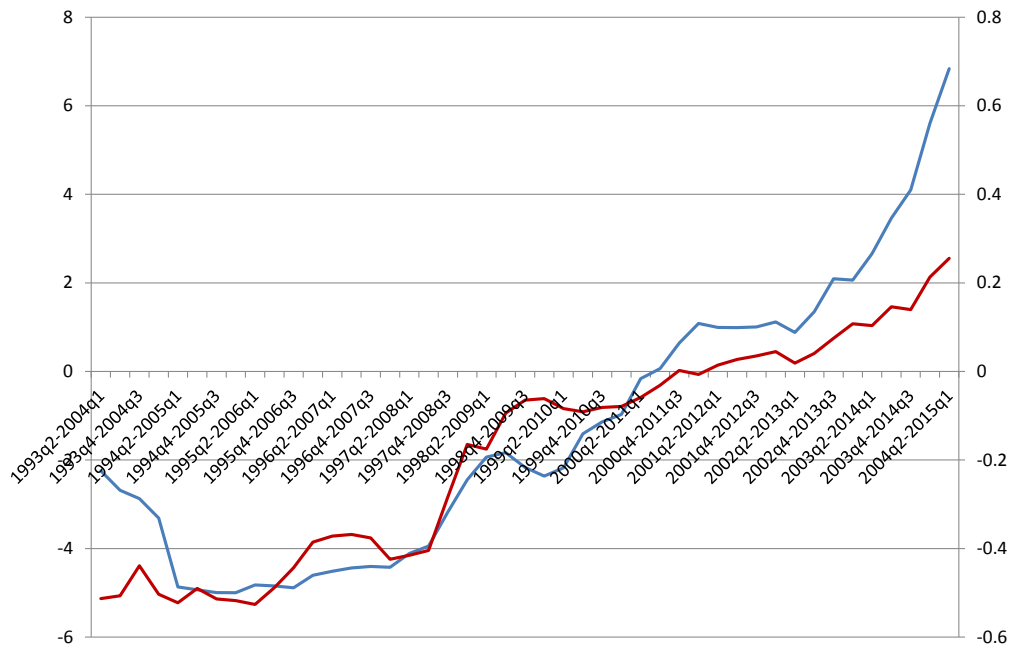

Figure 22: $\beta_{126}$ (blue) and $\operatorname{corr}(x, \pi)$ (red) - DM futures contracts

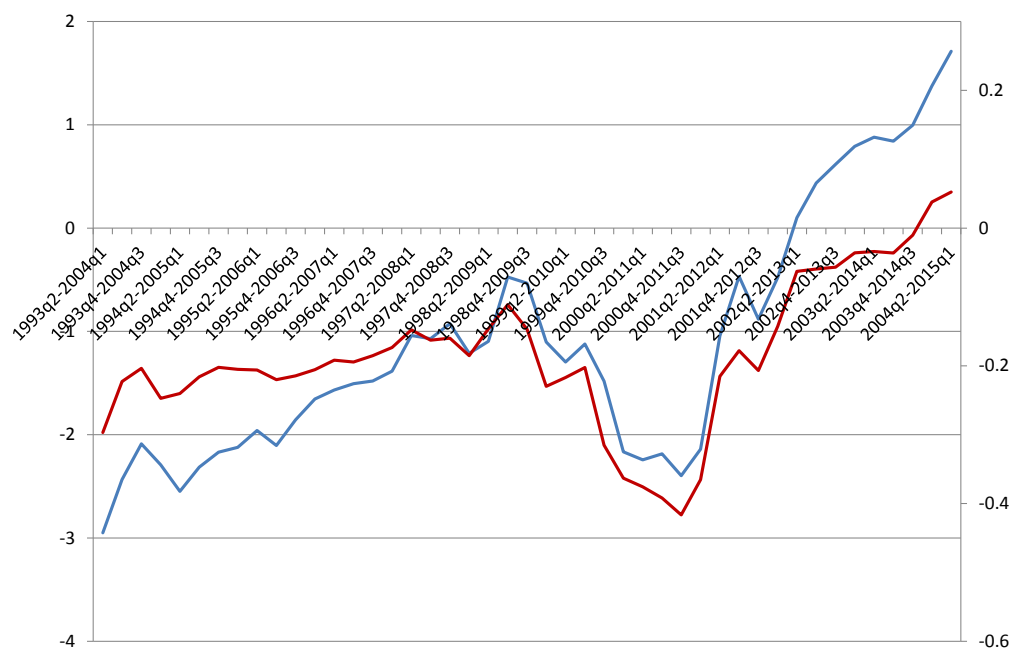

Figure 23: $\beta_{126}$ (blue) and $\operatorname{corr}(x, \pi)$ (red) - Yen futures contracts 


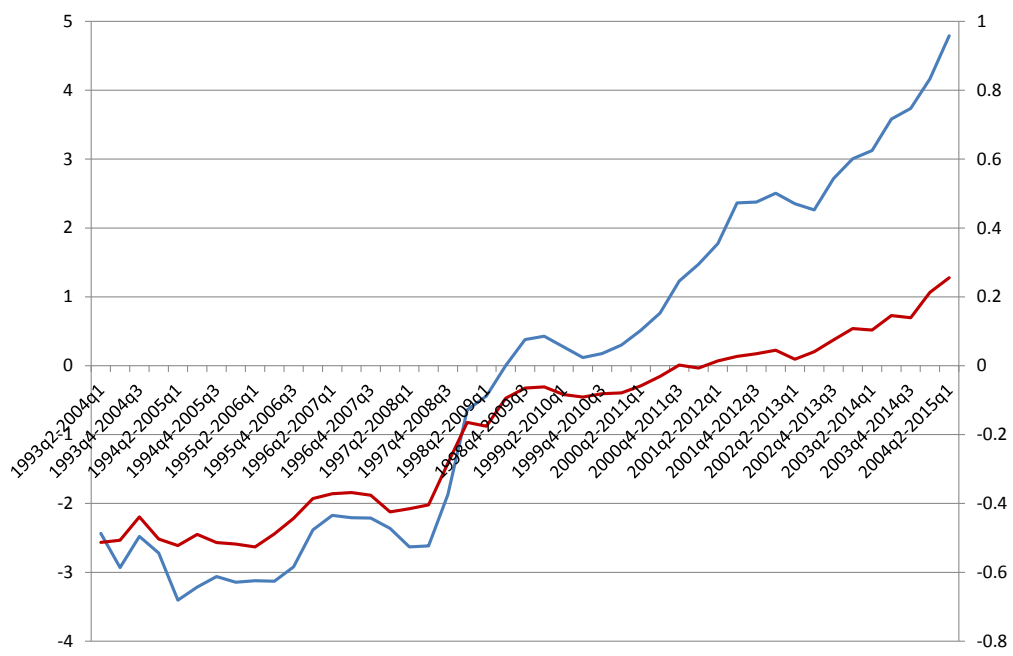

Figure 24: $\beta_{126}$ (blue) and $\operatorname{corr}(x, \pi)$ (red) - Pound futures contracts 